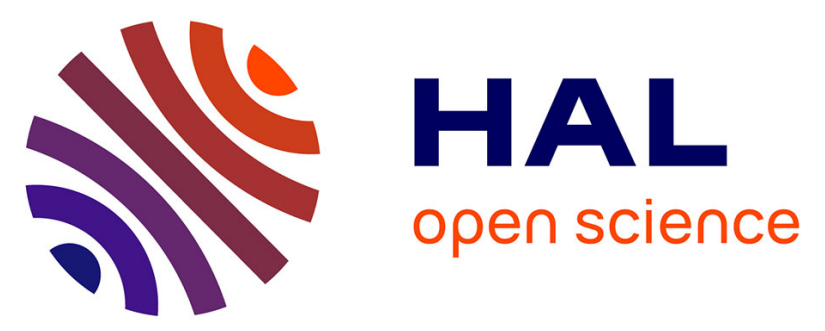

\title{
Electrical transport properties and modelling of electrostrictive resonance phenomena in $\mathrm{Ba} 2 / 3 \mathrm{Sr} 1 / 3$ TiO 3 thin films
}

Areski Ghalem, Laure Huitema, Aurelian Crunteanu, Mohamad Rammal, Lucian Trupina, Liviu Nedelcu, Gabriel Banciu, Perrine Dutheil, Catalin Constantinescu, Pascal Marchet, et al.

\section{To cite this version:}

Areski Ghalem, Laure Huitema, Aurelian Crunteanu, Mohamad Rammal, Lucian Trupina, et al.. Electrical transport properties and modelling of electrostrictive resonance phenomena in $\mathrm{Ba} 2 / 3 \mathrm{Sr}$ 1/3 TiO 3 thin films. Journal of Applied Physics, 2016, 120 (18), pp.184101-1-9. 10.1063/1.4966942 . hal-01394847

\section{HAL Id: hal-01394847 \\ https://hal-unilim.archives-ouvertes.fr/hal-01394847}

Submitted on 10 Nov 2016

HAL is a multi-disciplinary open access archive for the deposit and dissemination of scientific research documents, whether they are published or not. The documents may come from teaching and research institutions in France or abroad, or from public or private research centers.
L'archive ouverte pluridisciplinaire HAL, est destinée au dépôt et à la diffusion de documents scientifiques de niveau recherche, publiés ou non, émanant des établissements d'enseignement et de recherche français ou étrangers, des laboratoires publics ou privés. 
This manuscript was accepted by J. Appl. Phys. Click here to see the version of record.

A. Ghalem, ${ }^{1(*)}$ L. Huitema, ${ }^{1}$ A. Crunteanu, ${ }^{1}$, M. Rammal ${ }^{1}$, L. Trupina ${ }^{2}$,

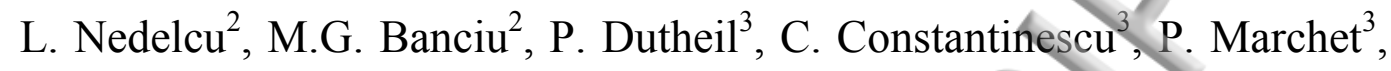

F. Dumas-Bouchiat ${ }^{3}$, C. Champeaux ${ }^{3}$

${ }^{1}$ XLIM UMR 7252 CNRS/ University of Limoges, 87060 Limoges, France.

${ }^{2}$ National Institute of Materials Physics, 077125 Bucharest-Magurele, Romania.

${ }^{3}$ University of Limoges, CNRS, SPCTS, UMR 7315, F-87068 Limoges, France.

*Corresponding author: Areski GHALEM

E-mail address: areski.ghalem@,unilim.fr

Keywords: Ferroelectrics, BST, Conduction mechanisms, Electrostrictive resonances, Interface layer

\section{ABSTRACT}

We present the conduction mechanisms of $\mathrm{Ba}_{2 / 3} \mathrm{Sr}_{1 / 3} \mathrm{TiO}_{3}$ thin films integrated in metal-insulator-metal (MIM) capacitors and the modelling of the frequency-dependent electrostrictive resonances (in the $100 \mathrm{MHz}-10 \mathrm{GHz}$ domain) induced in the devices upon applying different voltage biases. Au/BST/Ir MIM structures on MgO substrates have been fabricated and, depending on their specific polarization, we highlighted different conduction mechanisms in the devices. Depending on the dc bias polarity, the conduction current across the material shows a space-charge-limited-current behavior under negative polarization, while under positive bias the conduction obeys an electrode-limited Schottky-type law at the Au/ BST interface.

The application of an electric field on the device induces the onset of acoustic resonances related to electrostrictive phenomena in the ferroelectric material. We modeled these acoustic 
resonances over a wide frequency range, by using a modified Lakin model which takes into account the dispersions of acoustic properties near the lower electrode/ thin film interface.

\section{INTRODUCTION}

$\mathrm{Ba}_{\mathrm{x}} \mathrm{Sr}_{1-\mathrm{x}} \mathrm{TiO}_{3}$ (BST) thin films are receiving considerable consideration as highpotential solutions for the conception of tunable devices in the microwaves and even the millimeter-waves ${ }^{1-7}$. When integrated in capacitive metal-insulator-metal (MIM) structures, BST films are changing their permittivity upon application of a DC electric field, resulting in the modification of the overall capacitance of the MIM device with ratios up to $5: 1^{8}$. Different ferroelectric thin layer compositions have been studied in detail ${ }^{9-11}$. These barium contents can impose a specific state of the BST material (in ferroelectric or paraelectric forms) at room temperature.

The research presented in this paper (electrical and high-frequency characterization of BST material integrated in tunable MIM-type varactor devices) is a necessary step for the integration of the presented components in compact and low power consumption highfrequency devices. The final and specific goal is to realize a reconfigurable antenna exploiting the agility of BST materials integrated in MIM devices. The integration of a tunable BSTbased capacitance within an antenna will reconfigure its working frequency for wireless communication on the ISM band going from $2.4 \mathrm{GHz}$ to $2.5 \mathrm{GHz}$. To be competitive with other tunable components such as AsGa varactor diodes, the BST capacitors need to have low

losses while having a good tunability and reliability ${ }^{12-14}$. Two factors are directly influencing both the BST losses and reliability: leakage currents of the MIM capacitances and the onset acoustic resonances at high frequencies. The global understanding and characterisation of these two phenomena are important and necessary steps for improving the quality of the BST 
layer in order to obtain the best adapted capacitance value of the devices on the ISM band and, at the same time, the lowest losses in the same frequency band.

Depending on the electrode's type (noble metals, rutile-type oxides or complex perovskite oxides like $\mathrm{LaNiO}_{3}$ or $\mathrm{SrRuO}_{3}{ }^{15-17}$, typical conduction mechanisms proposed for BST thin film capacitors include film/electrodes interface- dominated Schottky emission ${ }^{18}$ bulk-related mechanisms like space-charge-limited conduction (SCLC) ${ }^{16}$ or Poole-Frenkel conduction ${ }^{20}$ etc. For MIM capacitive structures, the electrode nature is therefore influencing the properties of the devices. Moreover, a variation of both lattice parameter and thermal expansion coefficient between the electrode and the film can cause important variations of dielectric properties and increase significantly leakage current ${ }^{21,22}$. Thus, interfacial layers between electrodes (the upper and/or the lower one) and the BST film have a significant impact on the degradation of dielectric BST thin film ${ }^{20}$. The reason of this degradation can be explain by the bias drop across the interface, due to the occurrence of a depolarizing field near the electrodes. Indeed, when a dielectric material is submitted to an external electric field, the dipoles induced in the material generate a depolarizing electric field, which tends to oppose the external field and thus contributes to the fall of the polarization at the interfaces ${ }^{24-26}$. Consequently, the interfacial layer shows a much lower permittivity than the rest of the film and can be considered as a series parasitic capacitance, which may greatly reduce the material permittivity and therefore the capacitance of the BST device.

Besides the onset of leakage currents, an acoustic phenomenon occurs when applying DC bias voltages for tuning the BST permittivity within MIM structures. The magnitude of the applied electric fields breaks the central symmetry of the crystal and induces acoustic-type resonance phenomena ${ }^{27-30}$ which are a combination of electrostrictive and piezoelectric effects ${ }^{31-34}$. These bias-induced electrostrictive phenomena are resulting in non-linear effects such as instabilities of the device capacitance and increased losses at specific resonant 
frequencies in the microwave domain. Although these acoustic resonance phenomena can be appropriately used to develop voltage controlled resonators or filters ${ }^{35,36}$ they may become easily a critical issue for high-frequency applications where losses, stability and linearity of the agile capacitors are essential.

A better understanding of this phenomenon on a wide frequency range (especially at microwave frequencies) requires to take into account various material properties (thicknesses, permittivity, acoustic velocities and impedances, etc.), as well as device designs (type of electrodes, electrode/ BST film interfaces, etc.). Lakin et al ${ }^{37}$ developed a convenient analysis of these acoustic resonances induced by polarization fields. The model is using the electrical impedance description of each layer of the ferroelectric MIM capacitance considered as a parallel plate composite resonator. However, so far, the modeling of such acoustic phenomena was performed only for the first acoustic resonance appearing in the device response corresponding to a limited frequency domain ${ }^{38}$.

The present paper focuses on transport properties and mechanisms for leakage current of asymmetric $\mathrm{Au} / \mathrm{Ba}_{2 / 3} \mathrm{Sr}_{1 / 3} \mathrm{TiO}_{3} / \mathrm{Ir}$ ferroelectric capacitors as well on the broad frequency band modelling of their electrostrictive behavior at different applied biases. Although there is a significant number of results concerning the electrical properties of the Pt / BST interface ${ }^{39-}$ ${ }^{43}$, the electrical properties of the Ir/ BST system (Ir as bottom electrode) are less described in the literature

We also demonstrate, that the interfacial Ir electrode/ BST film layer plays a fundamental role within the Lakin formalism for properly model the additional secondary harmonic acoustic resonances of the electrostrictive responses in the MIM device, on a broader frequency domain. 


\section{EXPERIMENTAL PROCEDURE}

In order to characterise the electrical transport properties of the BST layers, we fabricated MIM structures and evaluate their current-voltage (I-V) characteristics. The fabrication process starts with the deposition of an optimized iridium bottom electrode $(100 \mathrm{~nm})$ by radiofrequency magnetron reactive sputtering, at $600^{\circ} \mathrm{C}$, on a $\mathrm{MgO}(100)$ substrate. It follows the deposition of the BST layer by pulsed laser deposition (PLD) from a $\mathrm{Ba}_{2 / 3} \mathrm{Sr}_{1 / 3} \mathrm{TiO}_{3}$ target using a $\mathrm{KrF}(248 \mathrm{~nm})$ excimer laser with a pulse rate of $10 \mathrm{~Hz}$ and a fluence of $4.5 \mathrm{~J} / \mathrm{cm}^{2}$. During deposition, the substrate was kept at $700^{\circ} \mathrm{C}$ in oxygen atmosphere (ambient pressure of $0.3 \mathrm{mbar}$ ). The deposition time varies between 30 and $60 \mathrm{~min}$ with a target-substrate distance of $5 \mathrm{~cm}$, resulting in BST film thicknesses between $200 \mathrm{~nm}$ and $1450 \mathrm{~nm}$. Following their deposition, the BST films were structured in square patterns $\left(100 \times 100 \mu \mathrm{m}^{2}\right)$ using a photolithography step and wet etching. A 200-nm thick gold (Au) electrode with 10 -nm thick $\mathrm{Ti}$ adhesion layer was finally thermally evaporated and patterned by a lift-off process on the top of the BST patterns. The surface of facing top and bottom electrodes is $30 \mu \mathrm{m} \times 30 \mu \mathrm{m}$ and the typical topology of the obtained MIM devices is depicted in Fig. 1.
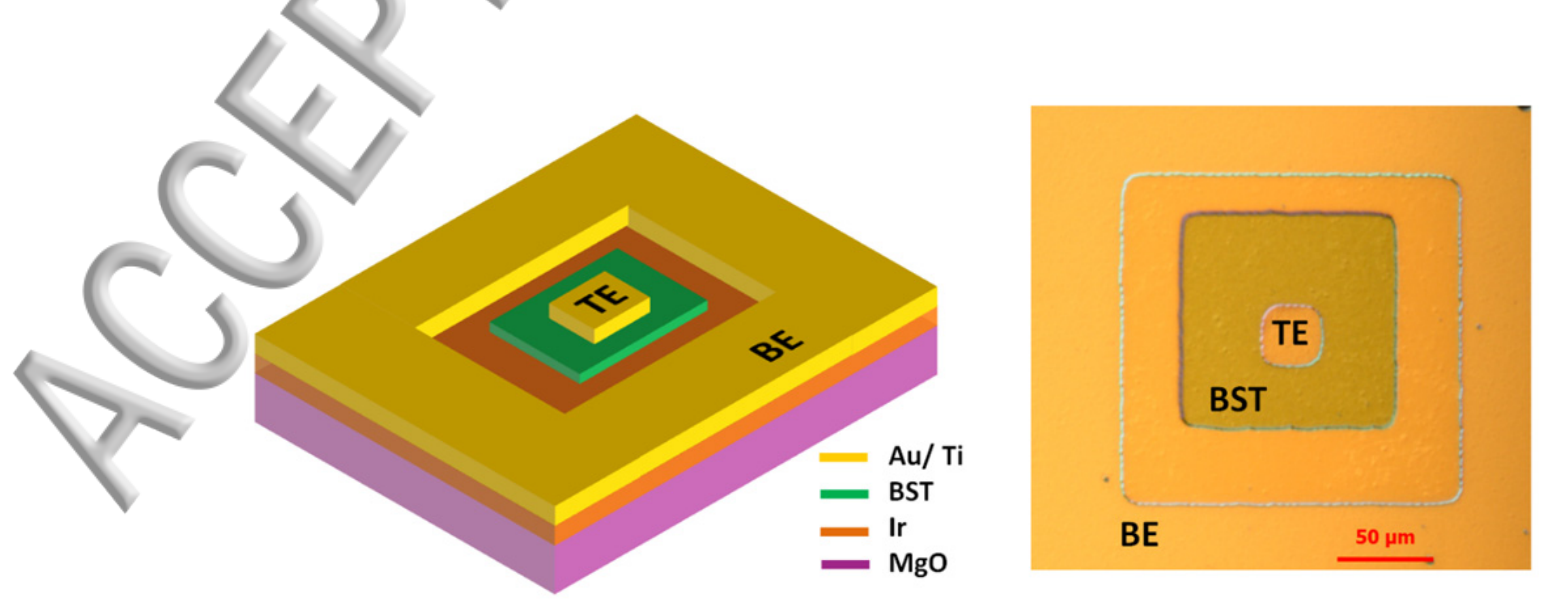
DC and high-frequency characterization studies of the fabricated ferroelectric devices have been conducted at different temperatures and for different polarization voltages. The DC characterization allows extracting the current-voltage ( $\mathrm{I}-\mathrm{V})$ characteristics of the MIM devices and was performed using a probe station connected to a Keithley 2612A sourcemeter. The device temperature was controlled using a Peltier module placed underneath. The response of the device in the high frequency domain $(100 \mathrm{MHz}-10 \mathrm{GHz})$ was recorded using a Rohde \& Schwarz vector network analyser (VNA) by measuring devices' reflection coefficient $\mathrm{S}_{11}$ (magnitude and phase) under different electrical fields applied between the top and the bottom electrodes (using a GSG (Ground-Signal-Ground) probe and an external bias Tee). For both the DC and RF measurements, the top gold ( $\mathrm{Au})$ electrode was biased either negatively or positively.

\section{RESULTS AND DISCUSSION}

\section{A. DC electrical conduction mechanisms}

The current density through the MIM device is defined as the ratio between the current and the square surface of facing electrodes can be deduced from the current-voltage measurements and plotted against the applied voltage. The interpretation of current density results reveals specific conduction mechanisms between metal (electrodes) and insulator (BST) which are directly linked to the metal/ insulator contact: neutral, blocking or ohmic. In this framework, two main conduction mechanisms can be distinguished: the conduction mechanism limited by electrodes/ film interfaces and the bulk limited conduction mechanism. The first one drives

the conduction when the metal/ insulator contact is either neutral or blocking while the second one is observed for ohmic contacts. 
The log-log current density as a function of the applied voltage characteristics have been obtained for I-V measurements performed on a $450 \mathrm{~nm}$-thick BST MIM device, for temperatures and DC bias voltages ranging between $293 \mathrm{~K}$ and $333 \mathrm{~K}$ and from $-4 \mathrm{~V}$ to $30 \mathrm{~V}$, respectively.

For negative bias voltages applied to the top Au electrode (with Ir electrode at 20V), Figure 2 (a) shows that the current density is rapidly increasing with the applied voltage. Since current values are limited by the sourcemeter to $1.5 \mathrm{~mA}$ (in order to avoid additional heating and current breakdown phenomena in the thin film due to high leakage currents), the value of $-4 \mathrm{~V}$ is the lowest applied voltage which could be measured.

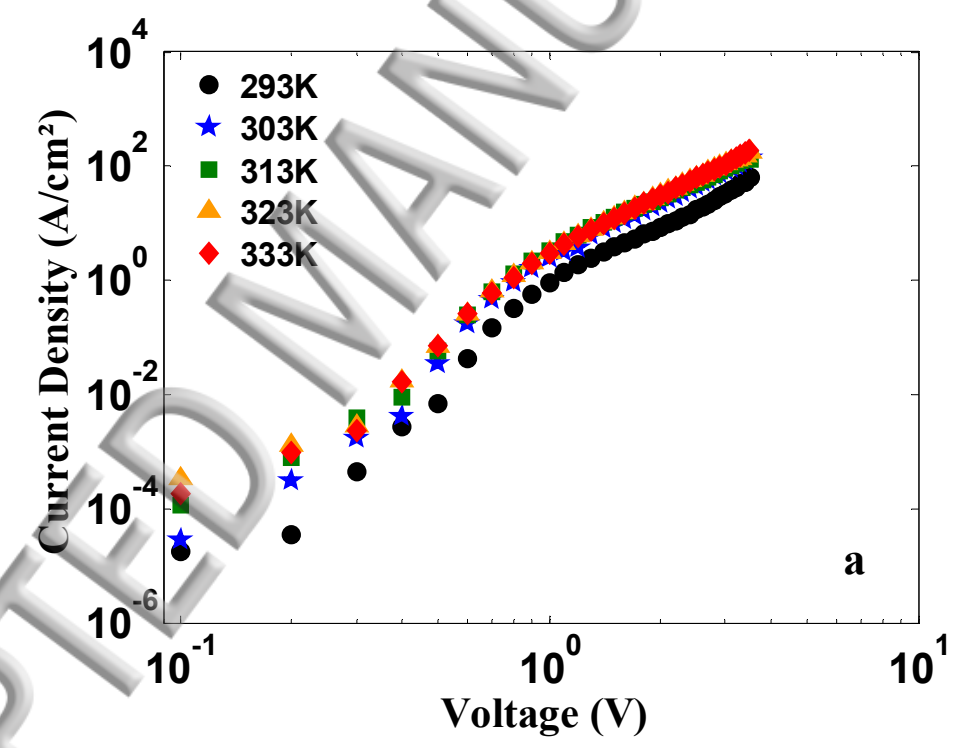




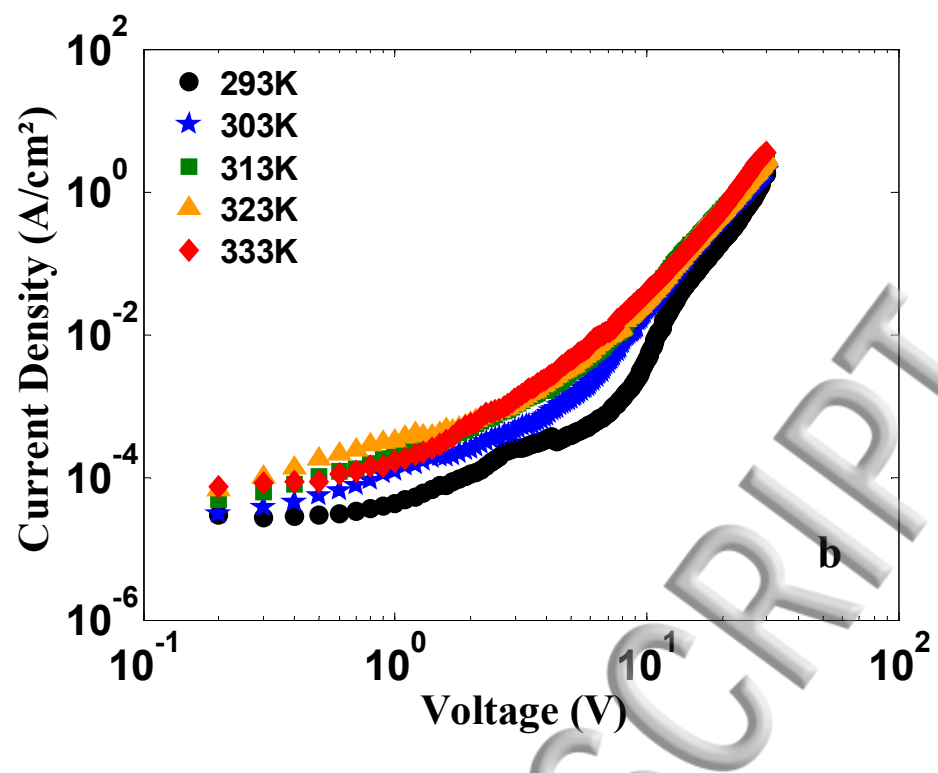

FIG. 2. Log-log representation of current density as a function of bias voltage applied to the top Au electrode for (a) negative and (b) positive bias voltages.

In this case, the bias voltage evolution and the temperature dependence can be related to a conduction mechanism limited by the interfaces and particularly to a Schottky emission mechanism ${ }^{18}$. Indeed, the Schottky effect corresponds to an injection of charges in the dielectric by passing above the potential barrier represented by the interface ${ }^{45}$. In this case, the current density follows a temperature and electrical field evolution described by the equation (1).

$$
\mathrm{J}=\mathrm{A}^{*} \mathrm{~T}^{2} \exp \left[-\frac{\mathrm{q}}{\mathrm{kT}}\left(\phi_{\mathrm{B}}^{0}-\sqrt{\frac{\mathrm{qE}}{4 \pi \varepsilon_{0} \varepsilon_{\mathrm{r}}}}\right)\right]
$$

Where $A^{*}$ is the Richardson's constant, $\mathrm{T}$ the temperature, $\mathrm{q} \phi_{\mathrm{B}}^{0}$ the potential barrier height, E the applied electric field and $\varepsilon_{\mathrm{r}}$ the relative dielectric permittivity of the BST material. The application of an electric field reduces the potential barrier and thus favours this type of charge injection. 


\section{This manuscript was accepted by J. Appl. Phys. Click here to see the version of record.}

The Schottky barrier is formed because the metal work function of gold electrode $\left(\Phi_{\mathrm{Au}}=5\right.$ $\mathrm{eV})$ is larger than the electron affinity of the BST film $\left(\chi_{\mathrm{BST}}=4.1 \mathrm{eV}\right)$. Consequently, in order to extract the apparent potential barrier at the BST $(450 \mathrm{~nm}) / \mathrm{Au}$ interface, a Schottky mechanism can be considered in the case where the applied bias voltage on the MIM device is negative. The equation (1) can be also expressed as follows:

$$
\ln \left(\frac{\mathrm{J}}{\mathrm{T}^{2}}\right)=\ln \left(\mathrm{A}^{*}\right)-\frac{\mathrm{q}}{\mathrm{kT}} \phi_{\text {app }}
$$

Where $\mathrm{q} \Phi_{\text {app }}$ is the apparent barrier height, defined according to the equation (3):

$$
\phi_{\mathrm{app}}=\phi_{\mathrm{B}}^{0}-\sqrt{\frac{\mathrm{qE}}{4 \pi \varepsilon_{0} \varepsilon_{\mathrm{r}}}}
$$

The apparent barrier height can be calculated with the slope of the $\ln \left(\mathrm{J} / \mathrm{T}^{2}\right)$ versus $1000 / \mathrm{T}$ representation which is plotted on Figure 3 for different bias voltages. These plots are reasonably linear in the investigated temperature domain.

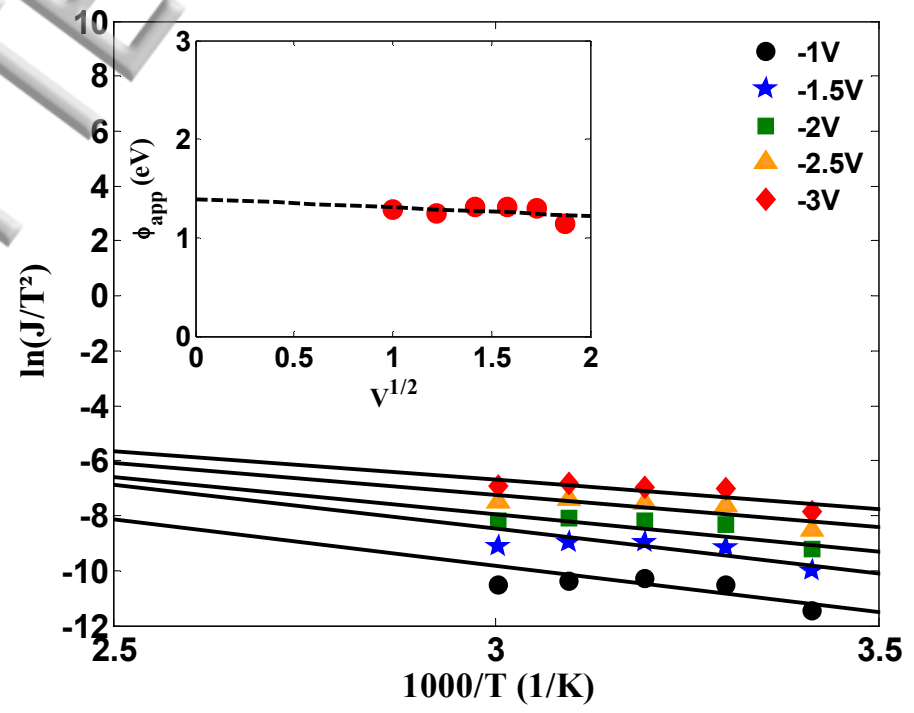


The Schottky barrier height is the energy difference between the metal work function of $\mathrm{Au}$ and the electron affinity of the BST film and corresponds to the height of barrier that have to cross the charges when passing into the dielectric. It can be obtained by extrapolating the electric field to zero in the description of the apparent barrier height. The dependence of the apparent barrier height on $\mathrm{V}^{1 / 2}$ is represented in the inset of Figure 3.

The extrapolation of the $\Phi_{\text {app }}=\mathrm{f}\left(\mathrm{V}^{1 / 2}\right)$ at $\mathrm{V}^{1 / 2}=0$ allows to extract the Schottky barrier height, with a value of $1.39 \mathrm{eV}$ at the $\mathrm{BST} / \mathrm{Au}$ interface. This value is in agreement with previous results on similar systems ${ }^{46}$.

The current-voltage evolution is different for a positive polarization (top Au electrode at positive bias and bottom Ir electrode at $0 \mathrm{~V}$, Figure 2-b). A different conduction mechanism may be clearly noted and the Figure 4 describes the log-log evolution of the current density as a function of the positive electric field for a MIM device integrating a 450-nm BST thick film, at $303 \mathrm{~K}$. We observe that for a low bias voltage, the leakage current densities were below $4 \times 10^{-4} \mathrm{~A} / \mathrm{cm}^{2}$ and the conduction mechanism is ohmic (slope $=1$ on Figure 4). Between $3.5 \mathrm{~V}$ and $5.5 \mathrm{~V}$, we clearly observe a transition to slope values greater than 1 , reflecting a nonohmic region. Under higher voltages, the $\log \mathrm{J}-\log \mathrm{V}$ curve slopes are equal or greater than 2 and define a bulk-type conduction regime which agrees well with the Space Charge Limited Current - (SCLC) with deep traps mechanism ${ }^{18,47 .}$ 


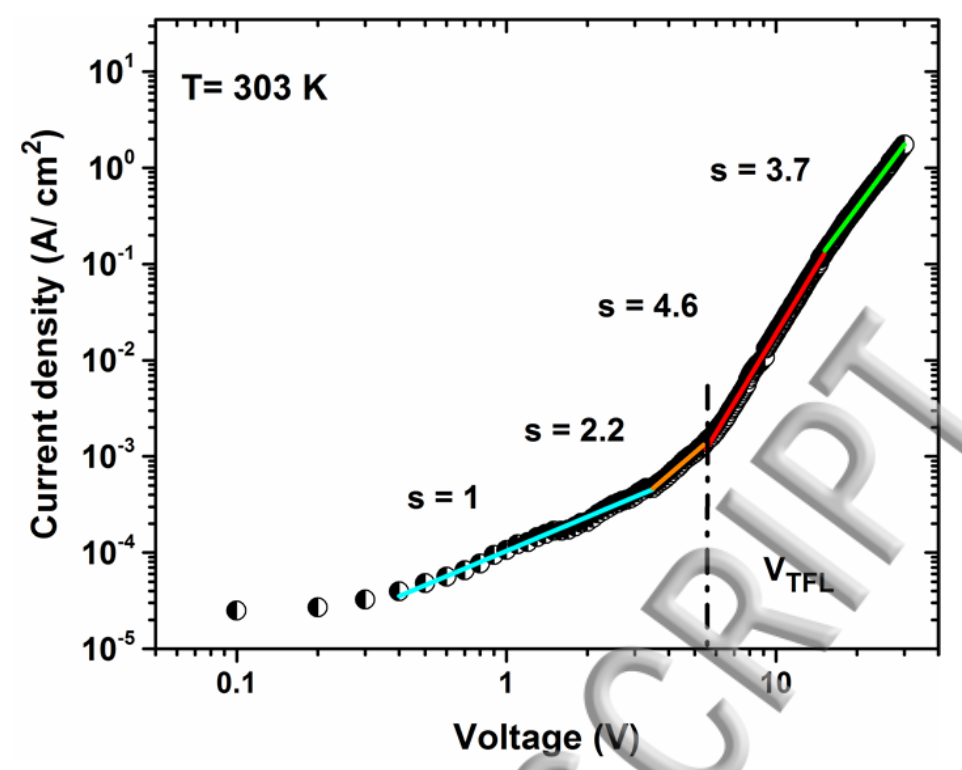

FIG. 4. Log-log plot of the current density vs the positive bias voltage for the MIM device integrating a 450-nm thick BST film, at $303 \mathrm{~K}$.

Indeed, the SCLC theory describes the density current evolution according to the electric field by the relation ${ }^{48}$ :

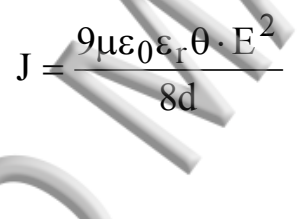

Where $\varepsilon_{\mathrm{r}}$ is the relative permittivity of the material, $\varepsilon_{0}$ the permittivity of the free space, $\mu$ the mobility, $\theta$ the ratio of free-to trapped electric charges and $d$ the film thickness.

At low bias voltages, the injected carrier density is negligible compared to the intrinsic carrier density and the conduction is ohmic (slope equal to 1 in the $\mathrm{J}-\mathrm{V} \log -\log$ representation on Figure 4). The SCLC regime occurs when the concentration of the built-in space charge cloud near the injected electrode is negligible against the injected charge density. The current density is following an $\mathrm{E}^{2}$ dependence described by the equation 4 (slope around 2 in the log$\log$ characteristics). 
As the electric field increases up to a voltage threshold (the trap-free voltage limit $\left(\mathrm{V}_{\mathrm{TFL}}\right)$ ), the amount of the injected charges is increasing and the density of free carriers injected into the active region becomes larger than its intrinsic charge density. Above $\mathrm{V}_{\mathrm{TFL}}$ all the trap levels are filled and the device enters in a different regime (trap-free SCLC or SCLC regime described by different trap level distributions) ${ }^{47}$.

If we consider the case of discrete shallow defect levels within the ferroelectric material (for voltages up to $\mathrm{V}_{\mathrm{TFL}}$ ), the density $\mathrm{N}_{\mathrm{t}}$ of the trapped charges can be expressed as:

$$
\mathrm{N}_{\mathrm{t}}=\frac{9}{8 \mathrm{q}} \varepsilon_{\mathrm{r}} * \varepsilon_{0} \frac{\mathrm{V}_{\mathrm{TFL}}}{\mathrm{d}^{2}}
$$

Where $\mathrm{q}$ is the charge of electron and $\mathrm{V}_{\mathrm{TFL}}$ can be experimentally deduced from Figure 4 . The extracted value of $\mathrm{V}_{\mathrm{TFL}}$ is $5.5 \mathrm{~V}$ corresponding to a $\mathrm{N}_{\mathrm{t}}$ value of $1.7 * 10^{20} \mathrm{~cm}^{-3}$ at $303 \mathrm{~K}$, which is consistent with previous reports on similar materials ${ }^{49}$.

The trap energy level $E_{t}$ can be further extracted from the expression of the ratio between the density of free and trapped electrons, $\theta$, which can be expressed as (6):

$$
\theta=\frac{N_{c} \exp \left[\left(E_{t}-E_{c}\right) / k T\right]}{g * N_{t}}
$$

Where $\mathrm{N}_{\mathrm{c}}$ is the effective density of states in the conduction band, $\mathrm{g}$ is a degeneracy factor $(\sim 2), E_{c}$ the energy level of conduction band, $\mathrm{k}$ the Boltzmann constant and $\mathrm{T}$ the temperature (K). Assuming $\mathrm{N}_{\mathrm{c}}=10^{21} / \mathrm{cm}^{3} 14,18,50$, we obtain the position of the energy level of traps with respect to the conduction band energy level, $\mathrm{E}_{\mathrm{c}}-\mathrm{E}_{\mathrm{t}}=0.16 \mathrm{eV}$, which is in the same order of magnitude with those reported previously ${ }^{49}$. 
Taking into account the conduction mechanisms inferred for both negative and positive polarizations, the proposed schematic energy band diagram of the Au/ BST/ Ir capacitor is presented on Figure 5.

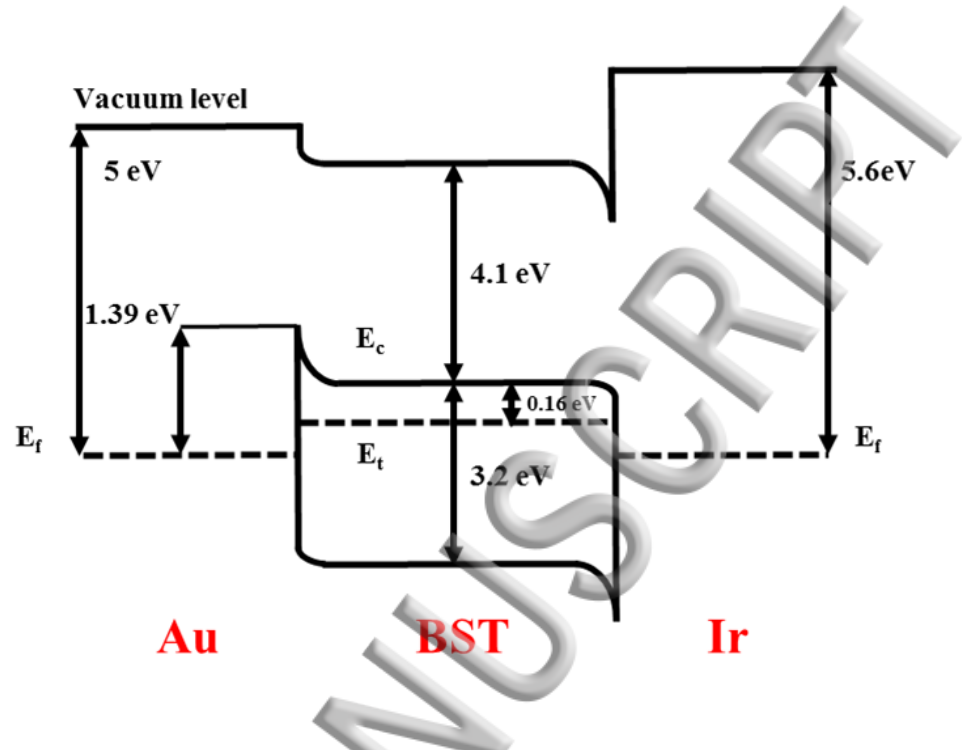

FIG. 5. Energy band diagram of the Au/BST/Ir capacitor.

We obtained similar results (analogous conduction mechanisms for an equivalent DC polarization) on MIM devices incorporating BST films with different thicknesses.

\section{B. High-frequency characterization of the MIM devices}

After analyzing the electrical characterization of BST thin films and the conduction phenomena at both metal-insulator interfaces, the next part of the paper will focus on the RF characterization of the BST thin films integrated in MIM tunable devices.

From the measurement of MIM devices reflection coefficients $S_{11}$ (magnitude and phase) under different applied voltages, we can extract both the global capacitance and the resistance values ${ }^{5}$ according to equations 7 and 8 , respectively. 


$$
\begin{gathered}
\mathrm{C}_{\text {meas }}=\frac{1}{\left|\mathrm{Z}_{0} \cdot \omega \cdot \operatorname{Im}\left(\frac{1+\mathrm{S}_{11}}{1-\mathrm{S}_{11}}\right)\right|} \\
\mathrm{R}_{\text {meas }}=\operatorname{Re}\left(\mathrm{Z}_{11}\right)=\operatorname{Re}\left(\mathrm{Z}_{0 *} \frac{1+\mathrm{S}_{11}}{1-\mathrm{S}_{11}}\right)
\end{gathered}
$$

The capacitance values variation with the electric field are plotted in Figure 6 for different thicknesses, of $200 \mathrm{~nm}, 450 \mathrm{~nm}$ and $1450 \mathrm{~nm}$ for the BST layer. Note that, the obtained films are highly oriented and exhibit a (100) preferred orientation with a small (111) contribution. Irrespective of the ferroelectric film thickness, the fabricated $\mathrm{Ba}_{2 / 3} \mathrm{Sr}_{1 / 3} \mathrm{TiO}_{3}$-based $\mathrm{MIM}$ devices show extremely high capacitance tuning. The relative capacitance variation goes up to $82 \%$ under an electric fields as low as $220 \mathrm{kV} / \mathrm{cm}$ which corresponds to an applied voltage of only $10 \mathrm{~V}$ for the 450-nm thick MIM device.

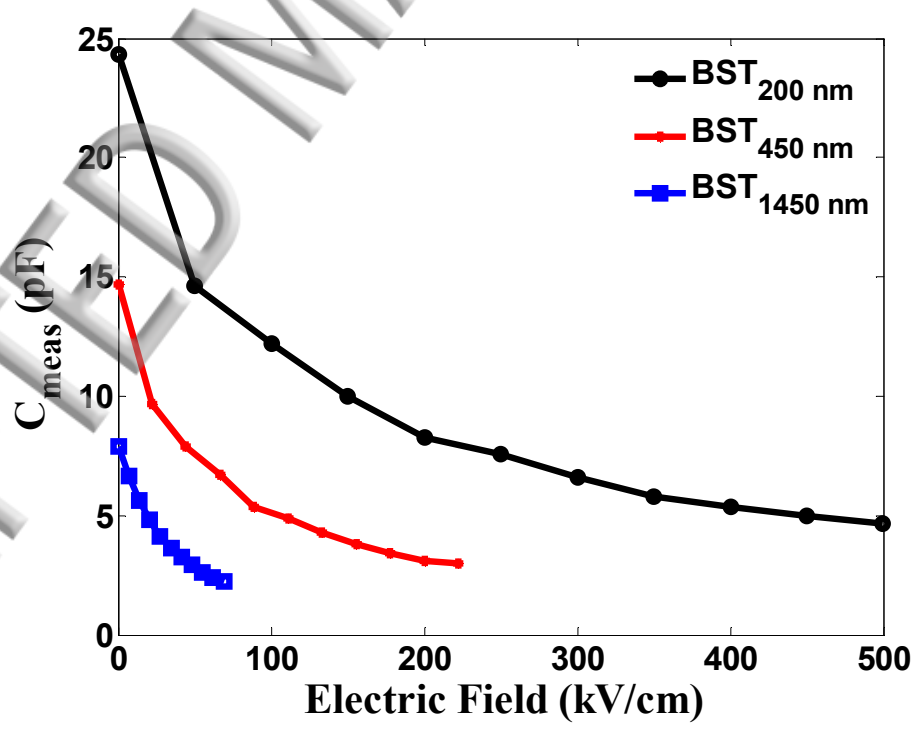

FIG. 6. Capacitance measurement as a function of electric field and for different thicknesses (maximum applied voltage bias of $10 \mathrm{~V}$ for all samples).

The state-of-the-art literature reports presented in the introduction section describes the relation between the degradation of both dielectric and acoustic properties of BST films with 
the presence of an interface layer. This degradation, introduced by the electrode: ferroelectric film interface layer can be quantified by analysing its impact on the overall capacitance of the MIM device. Following the formalism used in ${ }^{51}$, the capacitance measured for the MIM structure $\left(\mathrm{C}_{\text {meas }}\right)$ can be decomposed into the contribution of the BST film and that of the interfacial layer, according to the relationship (9):

$$
\frac{1}{C_{\text {meas }}}=\frac{1}{C_{f}}+\frac{1}{C_{i}}
$$

Where $C_{\text {meas }}$ corresponds to the measured capacitance and equals $\frac{\varepsilon_{0} \varepsilon_{\mathrm{r}} \mathrm{S}}{\mathrm{d}}$ ( $\mathrm{S}$ is the surface of the opposite electrodes and $d$ the thickness of the BST layer) and $C_{i}$ and $C_{f}$ are the interface and ferroelectric layer capacitances, respectively. If the thickness of the global structure (d) is much higher than the one of the interface layer, it can be approximated to the ferroelectric film thickness, i.e. and the equation 9 becomes equivalent to the equation (10):

$$
\frac{1}{C_{\text {meas }}}=\frac{d}{\varepsilon_{0} \varepsilon_{f} S_{f}}+\frac{1}{C_{i}}
$$

Therefore, the variation of the characteristic $1 / \mathrm{C}_{\text {meas }}=\mathrm{f}(\mathrm{d})$ for MIM structures with different global thicknesses is a straight line whose slope is inversely proportional to the intrinsic dielectric permittivity of the ferroelectric layer, $\varepsilon_{\mathrm{f}}$. The figure 7 describes the evolution of $1 / C_{\text {meas }}=f(d)$ curve for BST films with different thicknesses of $200 \mathrm{~nm}, 450 \mathrm{~nm}$ and 1450 $\mathrm{nm}$. 


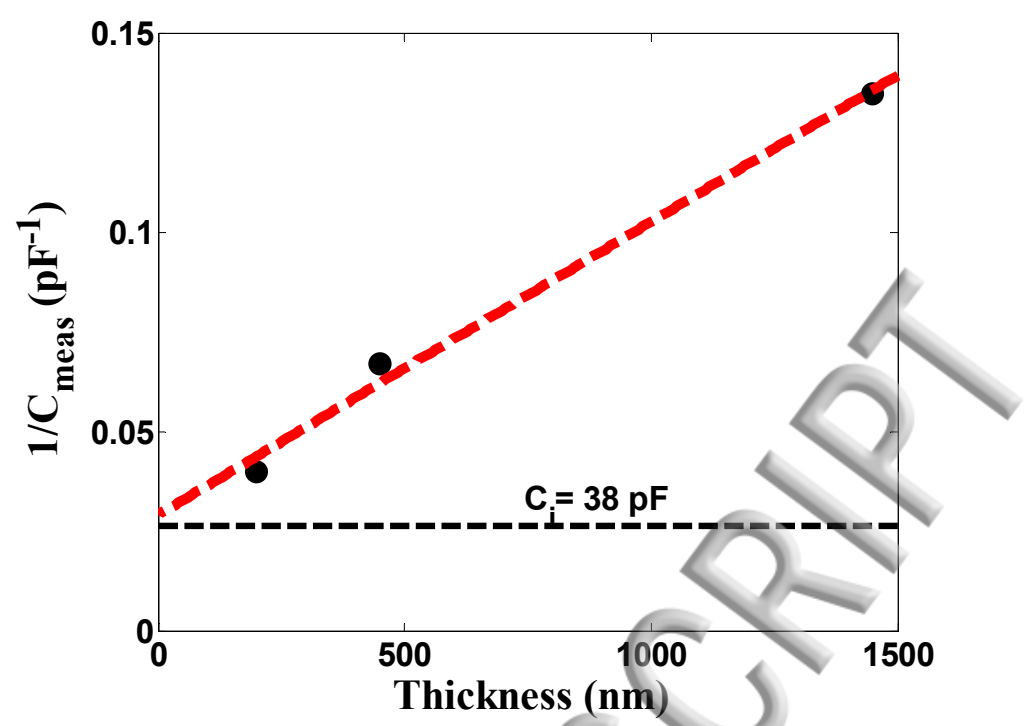

FIG. 7. Evolution of the inverse of capacitance $\left(1 / C_{\text {meas }}\right)$ as a function of BST film thicknesses.

The linear variation of the curve on Fig. 7 is in agreement with the series capacitance model that assumes the existence of regions with degraded dielectric properties close to the lower electrode/ferroelectric interface. Since $1 / \mathrm{C}_{\mathrm{i}}$ is directly deduced from the $\mathrm{y}$-intercept, we can calculate the interface capacitance, $\mathrm{Ci}=38 \mathrm{pF}$. Moreover, the intrinsic permittivity of the BST film (without the contribution of the interface layer) extracted from the slope is $\varepsilon_{\mathrm{f}}=2220$ and clearly exceeds the overall relative dielectric permittivity $\varepsilon_{\mathrm{r}}$ (around 1000 ) obtained by taking into account the contribution of the interface layer. We can therefore conclude that the interface between electrode and BST film contributes to the degradation of the dielectric properties and therefore cannot be disregarded when estimating the accurate dielectric properties of the ferroelectric material.

\section{Modelling of the electrostrictive phenomena in the ferroelectric-based MIM device}

Fig. 8 is plotting the measured overall resistance of the tunable device for the $450 \mathrm{~nm}$-thick

BST capacitor as a function of to the applied voltage. This resistance is equal to the real part of the device input impedance, $Z_{11}$, extracted from the measurement of reflection parameters $\mathrm{S}_{11}$ according to the equation 8 . Curves on Fig. 8 are exhibiting the onset of acoustic-like 
resonance effects when a DC-bias voltage is applied on the device, called electrostrictive resonances ${ }^{5,49}$. Therefore, the resistance values are corresponding to the global losses of the capacitor device, i.e. including BST film losses, electrodes losses and electrostrictive effects.

The electrostrictive resonances are reproducible and both their resonance frequencies and amplitudes are linked to the BST thickness ${ }^{8}$. Previous reports on these phenomena ${ }^{33}$ shows that the main electrostrictive resonance is inversely proportional to the BST thickness. However, the knowledge on only the first resonance frequency is not sufficient for the integration of BST materials in practical devices like reconfigurable antennas or filters. Indeed, in the case presented Fig. 8, the fabricated tunable capacitance could be exploited only on the $[3.8 \mathrm{GHz}-5.5 \mathrm{GHz}]$ frequency range since outside this domain the overall losses are too high. The need to predict the onset and frequency domain of electrostrictive resonance effects is therefore necessary for practical device implementations.

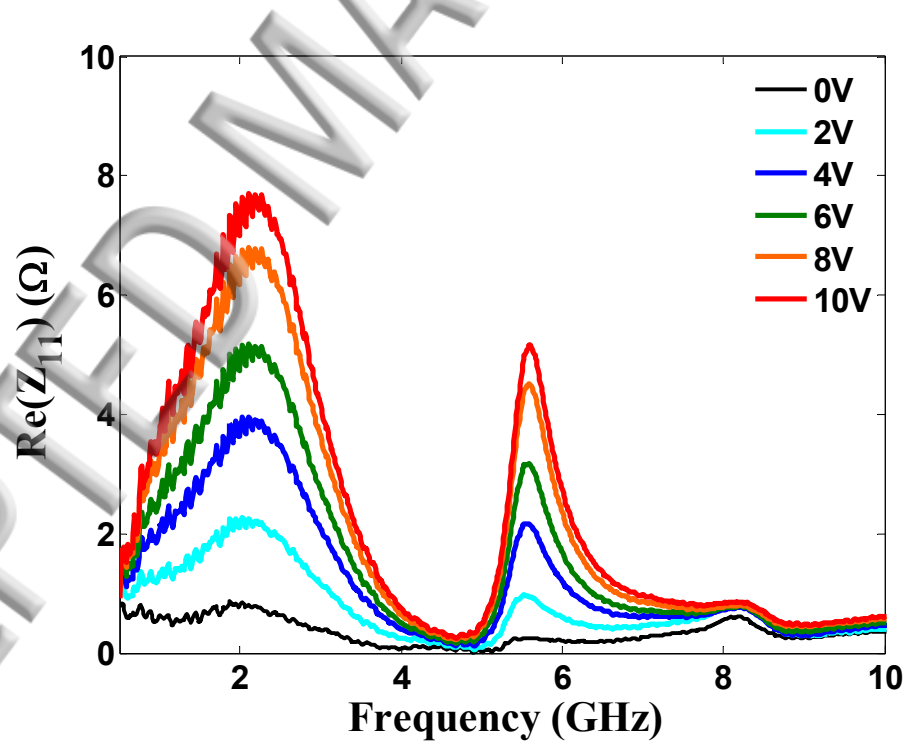

FIG. 8. Frequency evolution of the input impedance $Z_{11}$ as a function of the bias voltage for MIM device integrating a $450-\mathrm{nm}$ thick BST layer.

As indicated in the introduction part, the Lakin model ${ }^{53,54}$ is a simple and convenient approach for the simulation of acoustic/ electrostrictive behavior of ferroelectric layers integrating in MIM devices. The model is based on the acoustic transmission line 
transformation by considering the acoustic properties of each constituent layers (substrate, electrodes, ferroelectric film). The electric impedance of the MIM capacitor is described by the normalized acoustic load impedances $\mathrm{z}_{\mathrm{t}}$ and $\mathrm{z}_{\mathrm{b}}$ on each side of the ferroelectric thin film sandwiched between the metallic electrodes (Fig.9).

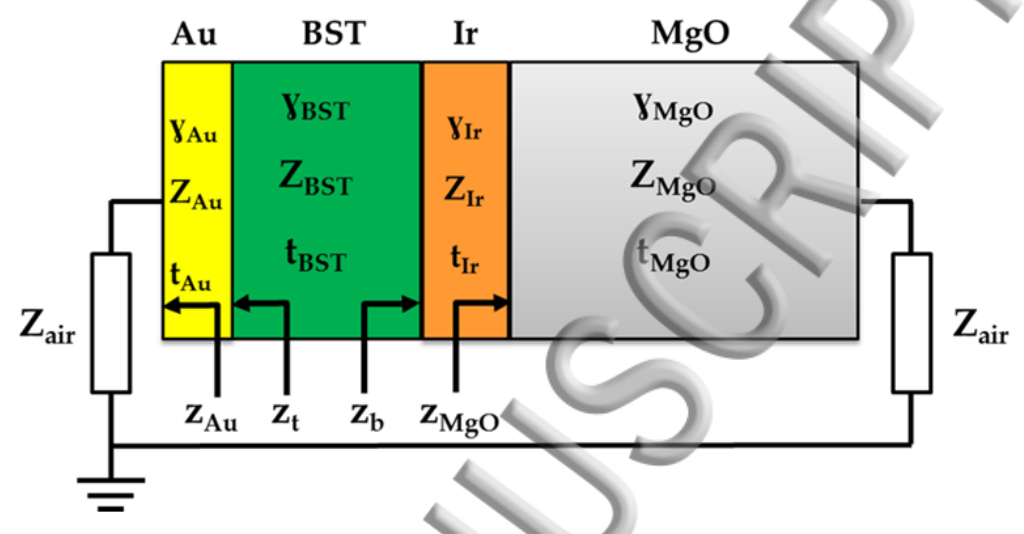

FIG. 9. Equivalent model of the ferroelectric MIM capacitor.

The equivalent acoustic impedance of the device is described by the equation (11):

$$
\mathrm{Z}_{\text {eq }}=\frac{1}{\mathrm{jC} \omega}\left[1-\mathrm{K}^{2}\left(\mathrm{~V}_{\mathrm{DC}}\right) * \frac{\tan \phi}{\phi}\left(\frac{\left(\mathrm{z}_{\mathrm{t}}+\mathrm{z}_{\mathrm{b}}\right) * \cos ^{2} \phi+\mathrm{j} \sin (2 \phi)}{\left(\mathrm{z}_{\mathrm{t}}+\mathrm{z}_{\mathrm{b}}\right) * \cos (2 \phi)+\mathrm{j}\left(\mathrm{z}_{\mathrm{t}} * \mathrm{z}_{\mathrm{b}}+1\right) \sin (2 \phi)}\right)\right]
$$

where $\omega$ is the angular frequency, $\mathrm{C}$ is the global device capacitance, $\Phi$ is the phase over the BST layer defined as $\phi=k . t / 2$ with $\mathrm{k}$ the wave vector and the BST thickness, $\mathrm{K}^{2}\left(\mathrm{~V}_{\mathrm{DC}}\right)$ is the electromechanical coupling coefficient depending on the applied bias voltage $\mathrm{V}_{\mathrm{DC}}, \mathrm{z}_{\mathrm{t}}=$ $\mathrm{Z}_{\mathrm{t}} / \mathrm{Z}_{\mathrm{BST}}, \mathrm{Z}_{\mathrm{b}}=\mathrm{Z}_{\mathrm{b}} / \mathrm{Z}_{\mathrm{BST}}$, where, $\mathrm{Z}_{\mathrm{BST}}$ is the acoustic impedance of the BST layer while $\mathrm{Zt}$ and $\mathrm{Z}_{\mathrm{b}}$ are the acoustic impedances of the top and bottom electrodes interfaces, respectively. $Z_{t}$ and $\mathrm{Z}_{\mathrm{b}}$ are calculating by using the classical transmission line equation (12):

$$
Z_{\text {int erface }}=Z_{L}\left(\frac{Z_{i}+Z_{L} \tanh \left(\gamma_{i} t_{i}\right)}{Z_{L}+Z_{i} \tanh \left(\gamma_{i} t_{i}\right)}\right)
$$


$\gamma_{i}=\alpha_{i}+j \beta_{i}$, is the propagation constant for each layer within the structure, with $\alpha_{i}$ the attenuation constant and $\beta_{\mathrm{i}}$ the phase constant depending on the acoustic velocity, $\mathrm{v}_{\mathrm{ac}}$ : $\beta_{\mathrm{i}}=$ $2 \pi \mathrm{f} / \mathrm{vac}_{\mathrm{ac}}$. Typical acoustic parameters for each layers composing the MIM device are described in Table 1.

Table 1. Geometrical and acoustic parameters of the layers considered in the MIM stack.

\begin{tabular}{|c|c|c|c|}
\hline Material & Thickness $(\mu \mathrm{m})$ & $\mathrm{v}_{\mathrm{ac}}(\mathrm{m} / \mathrm{s})$ & $\mathrm{Z}^{* 10^{6}}\left(\mathrm{~kg} / \mathrm{m}^{2} \mathrm{~s}\right)$ \\
\hline $\mathrm{Au}$ & 0.200 & 2200 & 62 \\
\hline $\mathrm{BST}$ & 0.45 & 4400 & 55.1 \\
\hline $\mathrm{Ir}$ & 0.100 & 3000 & 30 \\
\hline $\mathrm{MgO}$ & 500 & 8000 & 28.6 \\
\hline
\end{tabular}

The Lakin acoustic model has been implemented and the Fig. 10 is comparing the measurement and simulation results of the real part of the $Z_{11}$ parameter for different applied DC bias voltage.

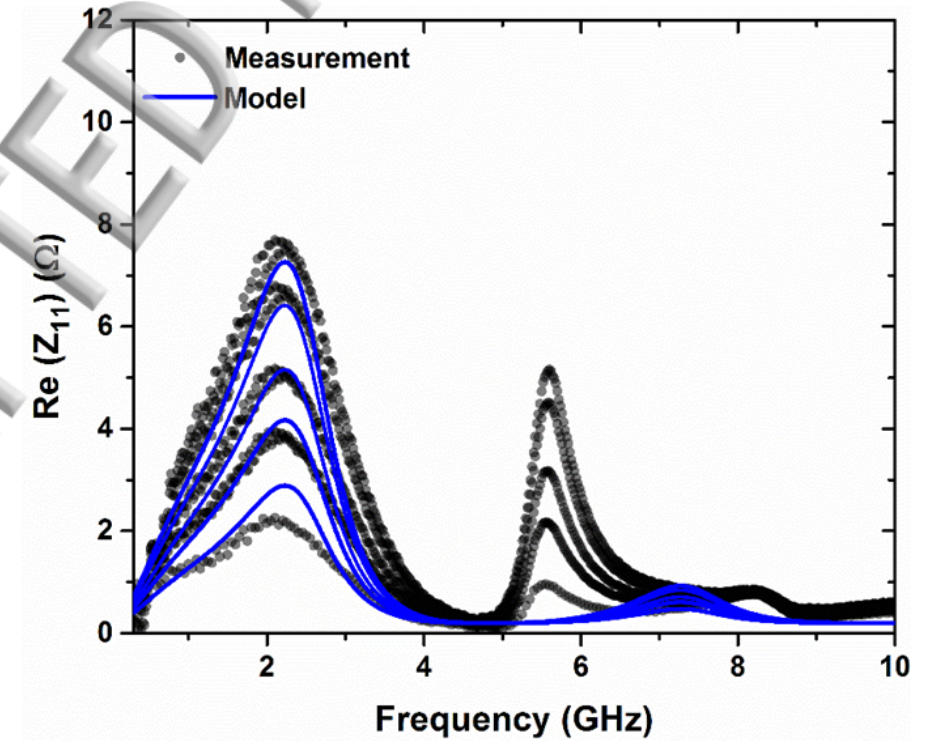

FIG. 10. Frequency evolution of the real part of the input impedance $Z_{11}$ (modelled and measured) for different bias voltages. 
As observed in Figure 10 and already confirmed for similar devices ${ }^{38,41}$, we noticed a good agreement between the implemented model and the experimental results for the main acoustic resonance peak, around $2.3 \mathrm{GHz}$. However, the current implementation of the model fails to correctly simulate the frequency position of the second acoustic harmonic which has a significant frequency shift and an important magnitude difference comparing with the measurement results. In order to explain this shift, Vorobiev et al ${ }^{55}$ discussed the possibility of a frequency dispersion of the acoustic velocity in the ferroelectric material, which would explain in their case the frequency position of the second harmonic resonance.

Following this hypothesis, we further considered the introduction of an interfacial layer (typically about $10-70 \mathrm{~nm}$ ) in the elecrostrictive model layers stack at the Ir/ BST interface, with dissimilar acoustic properties in comparison with the main BST layer.

The different interpretations proposed in the literature consider this interfacial layer as a low permittivity medium and referred to is as an intrinsic layer ${ }^{56,57}$. Moreover, Grossmann et al and Junquera et al ${ }^{58,59}$ show a suppression of ferroelectric properties in $\mathrm{Pb}(\mathrm{Zr}, \mathrm{Ti}) \mathrm{O}_{3}$ and $\mathrm{BaTiO}_{3}$ thin film due to the presence of such interfacial layers. Based on the deterioration of the ferroelectric properties at the Ir/ BST interface, it is conceivable to consider also a modification of the acoustic properties of this interface layer.

Taking into account all these considerations, the previous electrostrictive model stack was modified (inset in Fig. 11) by introducing an interface layer with optimized acoustic properties (layer thickness of $50 \mathrm{~nm}$ with an acoustic velocity of $2200 \mathrm{~m} / \mathrm{s}$, around two times less than the acoustic velocity of BST thin films). The comparison of the measurement results and the modelled input impedance of the modified layers stack within the MIM capacitance are represented on Figure 11. 


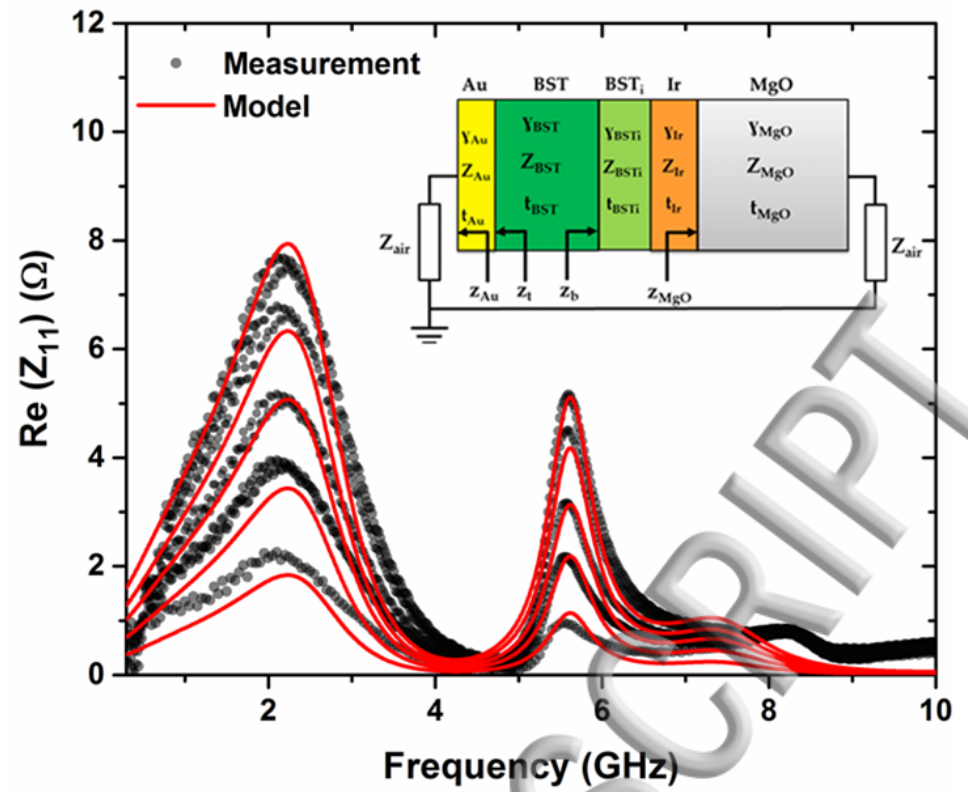

FIG. 11. Frequency evolution of the input impedance (modelled and measured) for different bias voltages considering an equivalent model of the MIM capacitor which is incorporating an Ir/ BST interface layer (inset).

It is obvious from the results presented in Figure 11 that by taking into account an interface layer at the $\mathrm{Ir}$ BST boundary having specific acoustic properties, the electrostrictive resonances induced in the device can be modelled not only for the first resonance peak but also for the successive harmonics, on a larger frequency band.

These results are important from the point of view of predicting and evaluating the overall device losses on a larger frequency domain. Indeed, it should be remind that the real part of the $\mathrm{Z}_{11}$ parameter equals the equivalent resistance of the tunable capacitance. Within the radiating element of a tunable antenna, a resistance higher than $2 \Omega$ is not acceptable therefore the electrostrictive resonances (frequency positions and amplitude) need to be predicted in order to dismiss them from the working frequency band of the antenna.

The impact of this interfacial layer on the global acoustic properties of ferroelectric MIM devices is still not completely documented, and its real nature remains a subject of discussion in the domain. Nevertheless, different hypothesis have been proposed concerning its origin such as: (i) the destruction of the polarization states near the interface ${ }^{54}$, ii) the formation of specific conduction mechanisms due to the difference in the band structure between the BST 
layer and the electrode ${ }^{18,60}$ or (iii) a thin layer adjacent to the electrode with particular microstructure which behaves like a series capacitor ${ }^{61}$.

The evaluation of the interface layer thickness using the electrostrictive model approach described above allows obtaining further information concerning the dielectric properties of this boundary layer.

In order to have a rough size of the permittivity near the interface, the thickness obtained from the electrostrictive effects simulation was reintroduced in the expressions defining the interface capacitance (eqs. 9 and 10). Indeed, from the curve on Figure 7 describing the variation of the BST measured capacitance $\left(1 / \mathrm{C}_{\text {meas }}\right)$ as a function of the ferroelectric layers thicknesses we may extrapolate it and extract the Y-intercept of the curve which is defining the capacitance associated with the interface layer (eq. 13), which can be expressed as:

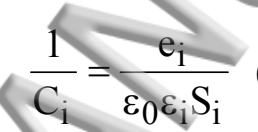

Where $\mathrm{Ci}$ is the interface capacitance, $\mathrm{e}_{\mathrm{i}}, \varepsilon_{\mathrm{i}}$ and $\mathrm{S}_{\mathrm{i}}$ are the thickness, the permittivity and the surface of the interface layer, respectively. Considering a value of $\mathrm{e}_{\mathrm{i}}=50 \mathrm{~nm}$, we obtained a permittivity value of $\varepsilon_{1} \sim 240$ which is significantly lower than that of the BST film. As indicated in the previous section, such a small permittivity of the $\mathrm{Ir} / \mathrm{BST}$ interface layer affects greatly the overall dielectric properties of the ferroelectric BST thin film and the capacitance values of the MIM device. Nevertheless, these results confirm the assumptions concerning the nature of this interface layer, which is expected to have highly dissimilar dielectric properties compared to the ferroelectric film, with a very low permittivity and degraded acoustic and ferroelectric behavior $58,62,63$. The rigorous simulation of electrostrictive phenomena on a broad frequency domain of such metal/ferroelectric/metal structures must therefore take imperatively into account the influence of the lower electrode/ ferroelectric film interface layer. 
This manuscript was accepted by J. Appl. Phys. Click here to see the version of record.

\section{CONCLUSION}

In this paper, we studied the conduction mechanisms MIM devices integrating a paraelectric $\mathrm{Ba}_{2 / 3} \mathrm{Sr}_{1 / 3} \mathrm{TiO}_{3}$ thin film with paraelectric behavior at room temperature. The negative and positive polarization of the device allowed determining the conduction laws (Schottky and SCLC, respectively) and the band diagram of the Au /BST / Ir/ MgO structure. The analysis of the dielectric properties of the BST films along with the modeling of electrostrictive acoustic resonance phenomena appearing in the MIM devices in the highfrequencies domain indicate the existence of an interface layer at the BST/ Ir boundary with dissimilar dielectric and acoustic properties when compared with the BST layer. We demonstrate that the modification of the electrostrictive Lakin model by including this interface layer in the overall layer stack of the device shows an excellent agreement between the modeled and the measured results over a wide frequency range. The modelling results presented here are relevant from the device integration point of view, by predicting and evaluating the overall device losses on a large frequency domain.

\section{ACKNOWLEDGEMENT}

This work was financially supported by the "Agence Nationale de la Recherche" (ANR)France and the National Authority for Scientific Research (ANCS)-Romania, under the project MAESTRO ANR-13-ISO3-001. 


\section{REFERENCES}

1 S. Courrèges, B. Lacroix, A. Amadjikpe, S. Phillips, Z. Zhao, K. Choi, A. Hunt, J.Papapolymerou, "Back-to-back tunable ferroelectric resonator filters on flexible organic substrates." IEEE Transactions on Ultrasonics. Ferroelectrics and Frequency. Control, 57, 2010 .

${ }^{2}$ R.De Paolis, S.Payan, M. Maglione, G.Guegan, F.Coccetti. "High-Tunability and High- Q Factor Integrated Ferroelectric Circuits up to Millimeter Waves" IEEE Transaction Microwave Theory and Technique, 63, 2015.

3 T.Kimura, H.Kobayashi, Y.Kishimoto, H.Kato, M.Inaba, K-Y.Hashimoto, T. Matsumura, H.Hirano, M.Kadota, M.Esashi, S.Tanaka. "S.Bandwidth-tunable filter consisting of SAW resonators and $\mathrm{BaSrTiO}_{3}$ varactors directly fabricated on a $\mathrm{LiTaO}_{3}$ wafer" IEEE International Ultrasonics Symposium (IUS), 2014. 
4 I.Vendik, V.Pleskachev, E.Zameshaeva, P.Turalchuk, D.Kholodnyak, I.Kolmakova, S.Zubko, I.Munina, V.Turgaliev, M.Sitnikova, M.Odit, X.Wang, N.Li, L.Sun, Y.He. Proceedings of the 43rd European Microwave Conference, 2013.

${ }^{5}$ G.Subramanyam, M-W.Cole, N-X.Sun, T-S.Kalkur, N-M.Sbrockey, G-S.Tompa, X.Guo, C.Chen, S-P.Alpay, G-A.Rossetti Jr., K.Dayal, L-Q.Chen, D-G.Schlom. "Challenges and opportunities for multi-functional oxide thin films for voltage tunable radio frequency/microwave components" Journal of Applied Physics, 114, 191301, 2013.

${ }^{6}$ H. Khassaf, N. Khakpash, F. Sun, N-M. Sbrockey, G-S. Tompa, T-S. Kalkur, S-P. Alpay. "Strain engineered barium strontium titanate for tunable thin film resonators" Applied Physics Letters, 104, 202902, 2014.

${ }^{7}$ N-M. Sbrockey, T-S. Kalkur, A. Mansour, H. Khassaf, H-Yu, M. Aindow, S-P. Alpay, G-S. Tompa "Switchable and tunable film bulk acoustic resonator fabricated using barium strontium titanate active layer and $\mathrm{Ta}_{2} \mathrm{O}_{5} / \mathrm{SiO}_{2}$ acoustic reflector" Applied Physics Letters, 109, 052902, 2014.

${ }^{8}$ A.Ghalem, M.Rammal, L.Huitema, A. Crunteanu, V. Madrangeas, P. Dutheil, F. Dumas Bouchiat, P. Marchet, C. Champeaux, L. Trupina, L. Nedelcu, M.G. Banciu "Ultra-High tunability of $\mathrm{Ba}_{(2 / 3)} \mathrm{Sr}_{(1 / 3)} \mathrm{TiO}_{3}$-based Capacitors under Low Electric Fields". IEEE Microwave and Wireless Components Letters, 26, pp 504-506, 2016.

${ }^{9}$ H. S. Kim, H. G. Kim, I. D. Kim, K. B. Kim, and J. C. Lee, "High tunability and lowmicrowave-loss $\mathrm{Ba}_{0.6} \mathrm{Sr}_{0.4} \mathrm{TiO}_{3}$ thin films grown on high-resistivity Si substrates using $\mathrm{TiO}_{2}$ buffer layers," Applied Physics Letters, 87, 212903, 2005.

${ }^{10}$ C. L. Chen, H. H. Feng, Z.Zhang, A. Brazdeikis, Z. J. Huang, W. K. Chu, C. W. Chu, F. A. Miranda, F. W. Van Keuls, R. R. Romanofsky, Y. Liou, "Epitaxial ferroelectric $\mathrm{Ba}_{0.5} \mathrm{Sr}_{0.5} \mathrm{TiO}_{3}$ thin films for room-temperature tunable element applications," Applied Physics Letters, 75, no. 3, pp. 412-414, 1999.

${ }^{11}$ D. A. Boyd, S. G. Hirsch, C. Hubbard, and M. W. Cole, "BST films grown by metal organic chemical vapor deposition incorporating real-time control of stoichiometry," Integr. Ferroelectr. 111, no.1, pp. 17-26, 2009.

12 D.Levasseur, H-B. El-Shaarawi, S. Pacchioni, A. Rousseau, S. Payan, G. Guegan, M. Maglione "Systematic investigation of the annealing temperature and composition effects on the dielectric properties of sol-gel $\mathrm{Ba}_{\mathrm{x}} \mathrm{Sr}_{1-\mathrm{x}} \mathrm{TiO}_{3}$ thin films" Journal of the European Ceramic Society, 33, pp 139-146 2013.

${ }^{13}$ W-Y. Hsu, J-D.Luttmer, R.Tsu, S.Summerfelt, M-Bedekar, T.Tokumoto, J.Nulman. "Direct current conduction properties of sputtered $\mathrm{Pt} /\left(\mathrm{Ba}_{0.7} \mathrm{Sr}_{0.3}\right) \mathrm{TiO}_{3} / \mathrm{Pt}$ thin films capacitors" Applied physics letters, 66, 2975, 1995.

14 C-S.Hwang, B-T.Lee, C-S.Kang, J-W.Kim, K-H.Lee, H-J.Cho, H.Horii, W-D.Kim, SI.Lee, Y-B.Roh, M-Y.Lee. "A comparative study on the electrical conduction mechanisms of $\left(\mathrm{Ba}_{0.5} \mathrm{Sr}_{0.5}\right) \mathrm{TiO}_{3}$ thin films on $\mathrm{Pt}$ and $\mathrm{IrO}_{2}$ electrodes" Journal of Applied Physics, 83, 3703, 1998. 
This manuscript was accepted by J. Appl. Phys. Click here to see the version of record.

15 T.Kawakubo, S.Komatsu, K.Abe, K.Sano, N.Yanase, N.Fukushima "Ferroelectric Properties of $\mathrm{SrRuO}_{3} /(\mathrm{Ba}, \mathrm{Sr}) \mathrm{TiO}_{3} / \mathrm{SrRuO}_{3}$ Epitaxial Capacitor “ Japanese Journal of Applied Physics, vol 37, 1998.

16 A.Srivastava, D. Kumar, R.K.Singh, " $\mathrm{LaNiO}_{3}$ as Contact Material for ( $\left.\mathrm{Ba}, \mathrm{Sr}\right) \mathrm{TiO}_{3}$ Dielectric Thin Films” Electrochemical and Solid-State letters, 2, pp 294-296, 1999.

${ }^{17}$ Y-K.Reddy, J.Wolfman, M.Gervais, F.Gervais, "Frequency dependent negative capacitance of $\left(\mathrm{Ba}_{0.6} \mathrm{Sr}_{0.4}\right)\left(\mathrm{Zr}_{\mathrm{x}} \mathrm{Ti}_{1-\mathrm{x}}\right) \mathrm{O}_{3}$ thin films grown on $\mathrm{La}_{0.9} \mathrm{Sr}_{1.1} \mathrm{NiO}_{4}$ buffered $\mathrm{SrTiO}$ substrate" Materials Science, pp 1-4, 2009.

18 S-T.Chang, J-Y.Lee. "Electrical conduction mechanism in high-dielectric-constant $\left(\mathrm{Ba}_{0.5}, \mathrm{Sr}_{0.5}\right) \mathrm{TiO}_{3}$ thin films" Applied physics letters, 80, 655, 2002.

${ }^{19}$ M-A. Khan, T-P. Comyn, A-J. Bell, "Deposition of $\mathrm{PbTiO}_{3}$ films on Pt/Si substrates using pulsed laser deposition” Journal European Ceramic Society, 28, 591, 2008.

${ }^{20} \mathrm{C}$-S.Hwang, "Bulk- or interface-limited electrical conductions in $\mathrm{IrO}_{2} /(\mathrm{Ba}, \mathrm{Sr}) \mathrm{TiO}_{3} / \mathrm{IrO}_{2}$ thin film capacitors" Journal of Materials Research, 16, pp 3476-3484, 2001.

${ }^{21}$ T-M.Shaw, Z.Suo, M.Huang, E.Liniger, R-B.Laibowitz, J-D.Baniecki. "The effect of stress on the dielectric properties of barium strontium titanate thin films" Applied Physics letters, 75, p 2129, 1999.

${ }^{22}$ S-Y.Wang, B-L.Cheng, C.Wang, S-A.Redfern, S-Y.Dai, K-J.Jin, H-B.Lu, Y-L.Zhou, Z-H Chen, G-Z.Yang, "Influence of Ce doping on leakage current in $\mathrm{Ba}_{0.5} \mathrm{Sr}_{0.5} \mathrm{TiO}_{3}$ films " Journal of Physics D: Applied Physics, 38, pp 2253-2257, 2005.

23 S-H. Paek, J.Won, K-S.Lee, J-S.Choi, C-S.Park, "Electrical and Microstructural Degradation with Decreasing Thickness of $(\mathrm{Ba}, \mathrm{Sr}) \mathrm{TiO}_{3}$ Thin Films Deposited by RF Magnetron Sputtering" Japanese Journal of Applied Physics, 35, 1996.

${ }^{24}$ Y.Wang, M-K.Niranjan, K.Janicka, J-P. Velev, M-Y.Zhuravlev, S-S.Jaswa, E-Y. Tsymbal. "Ferroelectric dead layer driven by a polar interface". Physical Review B, 82, 094114, 2010.

${ }^{25}$ N-A.Spaldin, "Fundamental Size Limits in Ferroelectricity” Science, 304, 1606, 2004.

26 R-R. Mehta, B-D. Silverman, J-T. Jacobs, "DC bias dependent shift of resonance frequencies in BST thin film membranes" IEEE International Symposium on the Applications of Ferroelectrics, pp 236-238, 2007.

27 A. Noeth, T. Yamada, V. Sherman, P. Muralt, A. Tangantsev, N. Setter "Modeling tunable bulk acoustic resonators based on induced piezoelectric effect in $\mathrm{BaTiO}_{3}$ and $\mathrm{Ba}_{0.25} \mathrm{Sr}_{0.75} \mathrm{TiO}_{3}$ films". Journal of Applied Physics, 103, 2008. 
This manuscript was accepted by J. Appl. Phys. Click here to see the version of record.

28 A. Vorobiev, S.Gevorgian, N.Martirosyan, M.Löffler, E.Olsson. "Intrinsically tunable ${ }_{0.67} \mathrm{BiFeO}_{3}-0.33 \mathrm{BaTiO}_{3}$ thin film bulk acoustic wave resonators"Applied Physics letters, vol 101, p 232903, 2012.

${ }^{29}$ S. Gevorgian, A. Vorobiev, T. Lewin. "dc field and temperature dependent acoustic resonances in parallel-plate capacitors based on $\mathrm{SrTiO}_{3}$ and $\mathrm{Ba}_{0.25} \mathrm{Sr}_{0.75} \mathrm{TiO}_{3}$ films: Experiment and modeling”. Journal of Applied Physics, 99, 124112, 2006.

30 A.Noeth, T.Yamada, A-K.Tagantsev, N.Setter. "Electrical tuning of dc bias induced acoustic resonances in paraelectric thin films capacitors". Journal of Applied Physics, 104, 094102, 2008.

${ }^{31} \mathrm{~S}$. Tappe, U. Bottger, and R. Waser, "Electrostrictive resonances in $\mathrm{Ba}_{0.7} \mathrm{Sr}_{0.3} \mathrm{TiO}_{3}$ thin films at microwave frequencies" Applied Physics Letters, 85, 624, 2004.

${ }^{32}$ W-P. Mason, B-T.Matthias, "Theoretical Model for Explaining the Ferroelectric Effect in Barium Titanate" Physical Review , 74, 1622, 1948.

${ }^{33}$ X. Zhu, J. D. Phillips, and A. Mortazawi, "A DC voltage dependent switchable thin film bulk wave acoustic resonator using ferroelectric thin film," 2007 IEEE MTT-S Int. Microwave Symp. Dig., pp. 671-674, 2007.

${ }^{34}$ W-P. Mason, “An Electromechanical Representation of a Piezoelectric Crystal used as a Transducer" Proceedings of the Institute of Radio Engineers (IRE), 23, pp 1252-1263, 1935.

${ }^{35}$ M. Schreiter, R. Gabl, D. Pitzer, R. Primig, W. Wersing, "Electro-acoustic hysteresis behaviour of PZT thin film bulk acoustic resonators", Journal of European Ceramic Society, 24, pp 1589-1592, 2004.

${ }^{36}$ P-B. Kirby, Q-X. Sua, E. Kornuroa, Q.Zhang, M.Imuraapb R-W. Whatmore, "PZT thin film bulk acoustic wave resonators and filters" IEEE International Frequency Control Symposium and PDA Exhibition, pp 687-694, 2001.

${ }^{37}$ K-M.Lakin, G-R.Kline, K-T Carron, "High-Q Microwave Acoustic Resonators and Filters" IEEE Transaction Microwave Theory Tech, 41, pp 2139-2146, 1993.

38 I.Vendik, P-A.Turalchuk, O-G.Vendik, J.Berge. "Modeling tunable bulk acoustic resonators based on induced piezoelectric effect in $\mathrm{BaTiO}_{3}$ and $\mathrm{Ba}_{0.25} \mathrm{Sr}_{0.75} \mathrm{TiO}_{3}$ films". Journal of Applied Physics, 103, 014107, 2008.

A.Vorobiev, J.Berge, S.Gevorgian, M.Löffler, E.Olsson. "Effect of interface roughness on acoustic loss in tunable thin film bulk acoustic wave resonators" Journal of Applied Physics, 110, 024116, 2011.

${ }^{40}$ D Levasseur, E Bouyssou, R De Paolis, A Rousseau, F Coccetti, G Guegan, S Payan and M Maglione "Systematic tuning of the conduction mechanisms in ferroelectric thin films" Journal of Physics: Condensed Matter, 25, 2013. 
This manuscript was accepted by J. Appl. Phys. Click here to see the version of record.

${ }^{41}$ B.Ivira, A.Reinhardt, E.Defay, M.Aid. "Integration of electrostrictive $\mathrm{Ba}_{0.7} \mathrm{Sr}_{0.3} \mathrm{TiO}_{3}$ thin films into Bulk Acoustic Wave resonator for RF-frequency tuning under DC bias" IEEE International Frequency Control Symposium, pp 254-258, 2008.

${ }^{42}$ A-G.Altynnikov, A-G.Gagarin, M-M.Gaidukov, A.Tumarkin, P-K.Petrov, N. Alford, A-B. Kozyrev. "Suppression of slow capacitance relaxation phenomenon in $\mathrm{Pt} / \mathrm{Ba}_{0.3} \mathrm{Sr}_{0.7} \mathrm{TiO}_{3} / \mathrm{Pt}$ thin film ferroelectric structures by annealing in oxygen atmosphere" Applied physics letters, 104, 042903, 2014.

${ }^{43}$ W-Y. Hsu, J-D.Luttmer, R.Tsu, S.Summerfelt, M-Bedekar, T.Tokumoto, J.Nulman. "Direct current conduction properties of sputtered $\mathrm{Pt} /\left(\mathrm{Ba}_{0.7} \mathrm{Sr}_{0.3}\right) \mathrm{TiO}_{3} / \mathrm{Pt}$ thin films capacitors" Applied physics letters, 66, 2975, 1995.

44 B.Mešić, H.Schroeder "Integration of perovskite oxide dielectrics into complementary metal-oxide-semiconductor capacitor structures using amorphous TaSiN as oxygen diffusion barrier” Journal of Applied Physics, 110, 064117, 2011.

${ }^{45}$ L.Pintilie, I. Vrejoiu, D. Hesse, G. LeRhun, M. Alexe. "Ferroelectric polarization-leackage current relation in high quality epitaxial $\mathrm{Pb}(\mathrm{Zr}, \mathrm{Ti}) \mathrm{O}_{3}$ ” Physical Review $\mathrm{B}, \mathbf{7 5}, 2007$.

${ }^{46}$ J.Shin, J.Park, C-S.Hwang, H-J.Kim. "Dielectric and electrical properties of sputter grown (Ba,Sr)TiO 3 thin films” Journal of Applied Physics, 86, 506, 1999.

${ }^{47}$ J. Sun, X-J. Zheng, W.Yin, M. H. Tang, W. Li. "Space-charge-limited leakage current in high dielectric constant and ferroelectric thin films considering the field-dependent permittivity” Applied Physics letters, 97, 2010.

${ }^{48}$ S.M.Sze, Physics of Semiconductor Device, $2^{\text {nd }}$ ed. (Wiley, New-York), 1981.

${ }^{49}$ C-J.Peng, S-B.Krupanidhi "Structures and electrical properties of barium strontium titanate thin films grown by multi-ion-beam reactive sputtering technique", Journal of Materials Research, 10, pp 708-726, 1995.

${ }^{50}$ T.Baiatu, R.Waser, K-H.Härdt "dc Electrical Degradation of Perovskite-Type Titanates: III, A Model of the Mechanism” Journal of American Ceramic Society, 73, pp 1663-1673, 1990.

${ }^{51}$ R. Bouregba, G. Le Rhun, G. Poullain, G. Leclerc, "Investigation of thickness dependence of the ferroelectric properties of $\mathrm{Pb}\left(\mathrm{Zr}_{0.6} \mathrm{Ti}_{0.4}\right)$ thin-film capacitors" Journal of Applied Physics, 99, 034102, 2006.

S.Gevorgian, A.Vorobiev, J.Berge "Electromechanical Modelling and Reduction of the Electroacoustic Losses in Parallel-Plate Ferroelectric Varactors" Proceeding of the $36^{\text {th }}$ European Microwave conference, pp 851-853, 2006.

${ }^{53}$ K. M. Lakin, G. R. Kline, and K. T. McCarron, "High-Q microwave acoustic resonators and filters," IEEE Trans. Microw. Theory Tech., 41, no. 12, pp. 2139-46, 1993. 
54 K. M. Lakin, "Thin film resonator technology," IEEE Transaction Ultrasonics, Ferroelectrics and Frequency Control, 52, no. 5, pp. 707-716, 2005.

55 A.Vorobiev, S.Gevorgian "Composite ferroelectric FBARS that are switchable between the first and second harmonics: experimental demonstration" IEEE Trans. Ultrason.,Ferroelect., Freq. Contr., 62, no. 3, pp. 565-575, 2015.

${ }^{56}$ C. Zhou, D-M. Newns, "Intrinsic dead layer effect and the performance of ferroelectric thin film capacitors" Journal of Applied Physics, 82, 3081, 1997.

${ }^{57}$ K. Natori, D.Otani, M. Sano, "Thickness dependence of the effective dielectric constant in a thin film capacitor" Applied Physics Letters, 73, 632, 1998.

${ }^{58}$ M. Grossmann, O. Lohse, D.Bolten, U. Boettger, T. Schneller, R. Waser "Interface-related decrease of the permittivity in $\mathrm{PbZr}_{\mathrm{x}} \mathrm{Ti}_{1-\mathrm{x}} \mathrm{O}_{3}$ thin films" Applied Physics Letters, 80, 1427, 2002.

${ }^{59}$ J.Junquera, P.Ghosez, "Critical thickness for ferroelectricity in perovskite ultrathin films" Letters to nature, 422, 506, 2003.

${ }^{60}$ C-S. Hwang, B-T. Lee, C-S. Kang, K-H. Lee, H. Cho, H. Hideki, W-D. Kim, S-I. Lee, MY. Lee, "Depletion layer thickness and Schottky type carrier injection at the interface between Pt electrodes and (Ba, Sr) $\mathrm{TiO}_{3}$ thin films" Journal of Applied Physics, 85, 287, 1999.

${ }^{61}$ C.Basceri, S-K.Streiffer, A-I. Kingon, R.Waser, "The dielectric response as a function of temperature and film thickness of fiber-textured $(\mathrm{Ba}, \mathrm{Sr}) \mathrm{TiO}_{3}$ thin films grown by chemical vapor deposition" Journal of Applied Physics, 82, pp 2497-2504, 1997.

62 A.A. Sirenko, C.Bernhard, A.Golnik, A.M. Clark, J.Hao,W.Si, X. X. Xi "Soft-mode hardening in $\mathrm{SrTiO}_{3}$ thin films" Letters to nature, 404, pp 373-376, 2000.

${ }^{63}$ C-T. Black, J-J. Welser, "Electric-Field Penetration Into Metals: Consequences for HighDielectric-Constant Capacitors" IEEE Transactions on electronic devices, 46, pp 776-780, 1999. 


\section{s)

$$
\text { क् }
$$

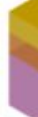

$\mathrm{Au} / \mathrm{Ti}$

BST

Ir

MgO
TE

BST
BE

$50 \mu \mathrm{m}$ 


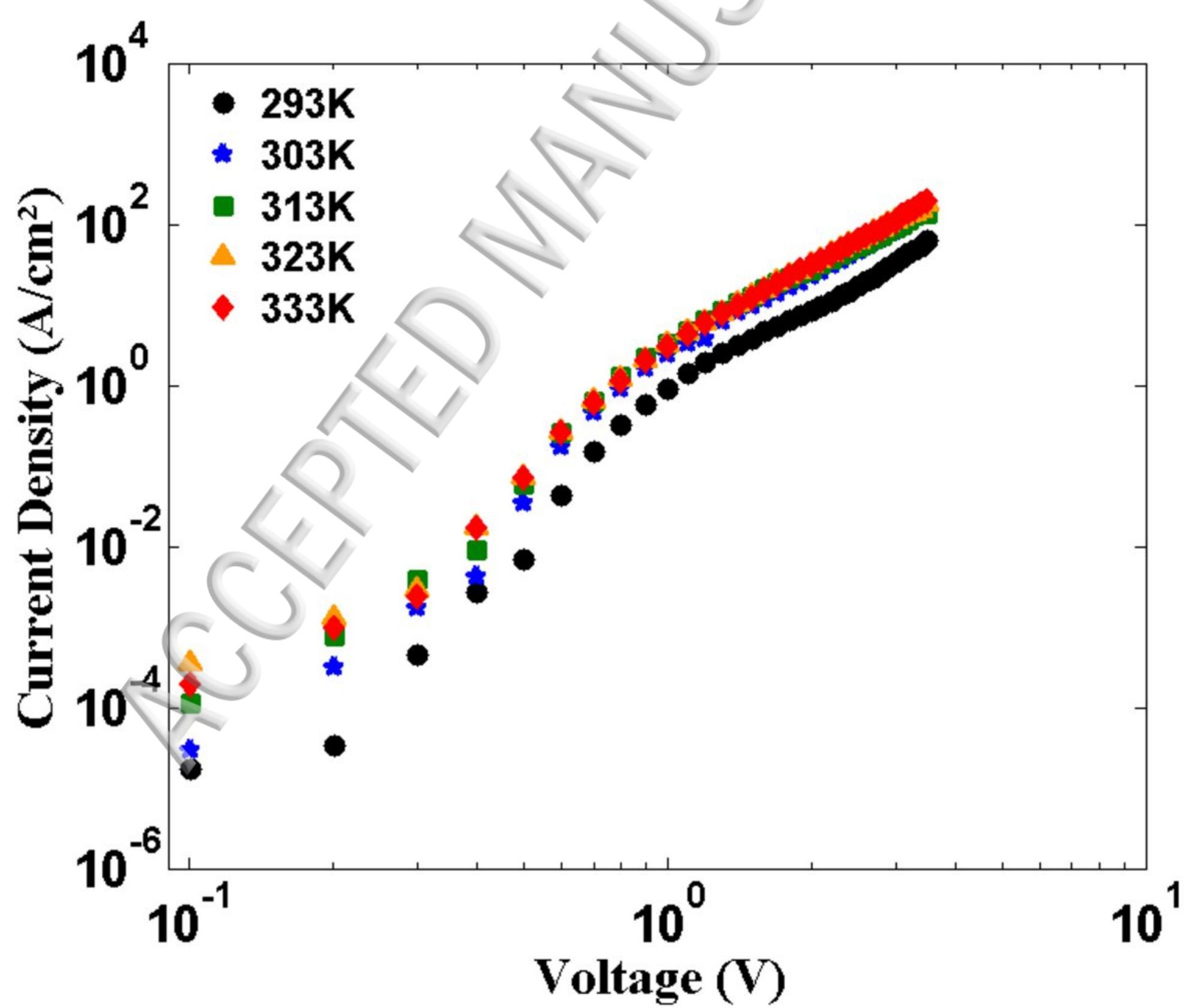




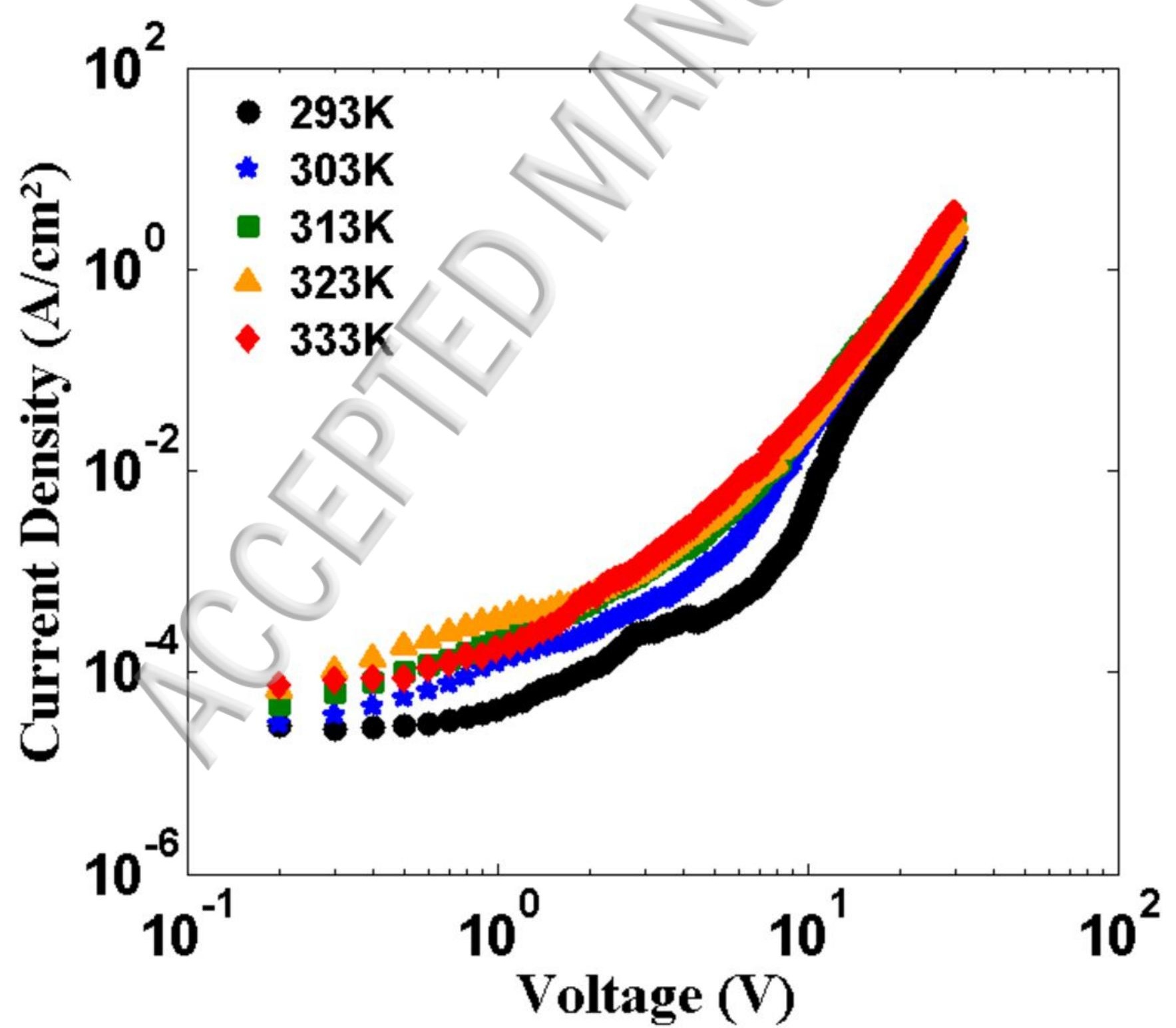




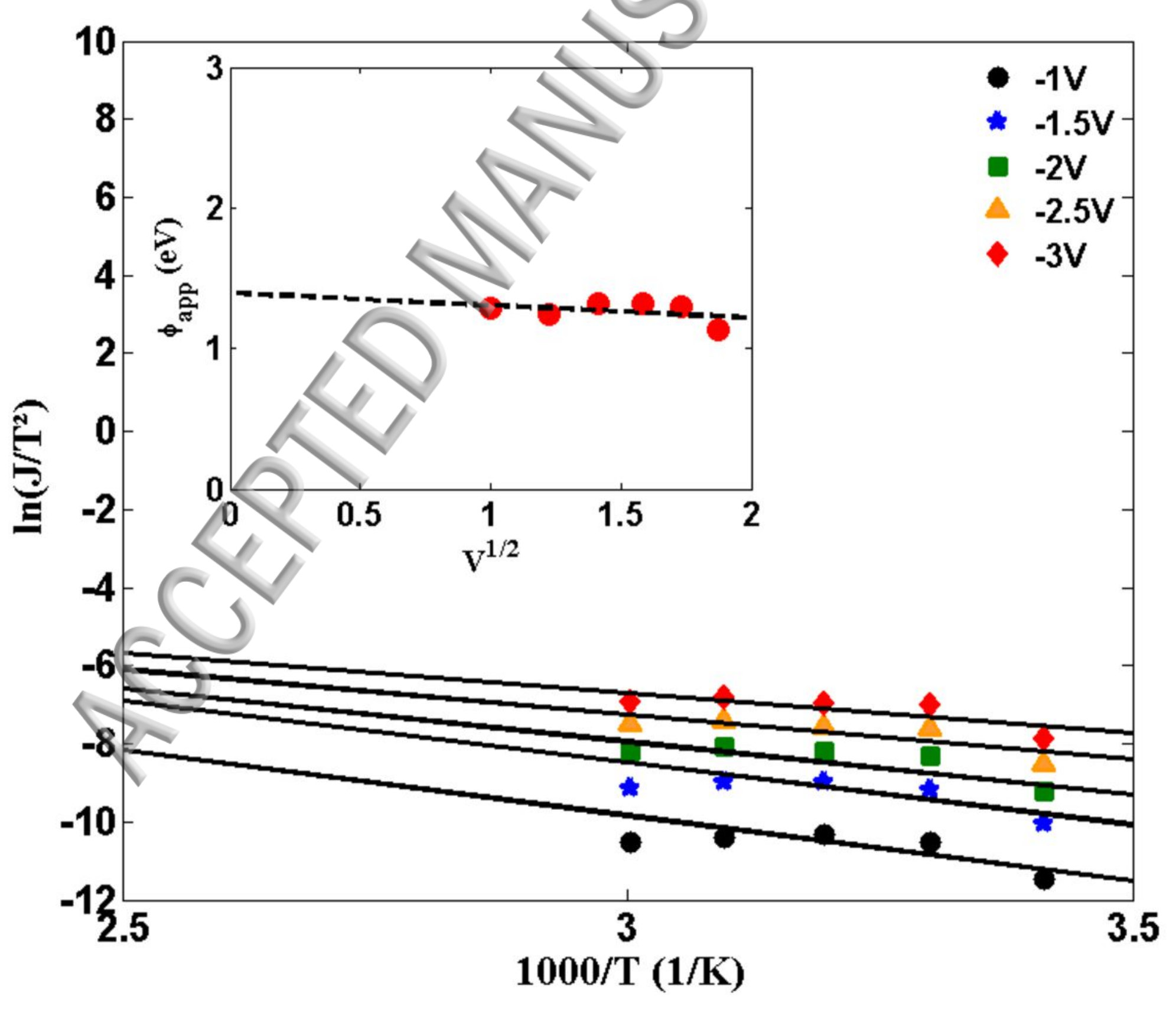




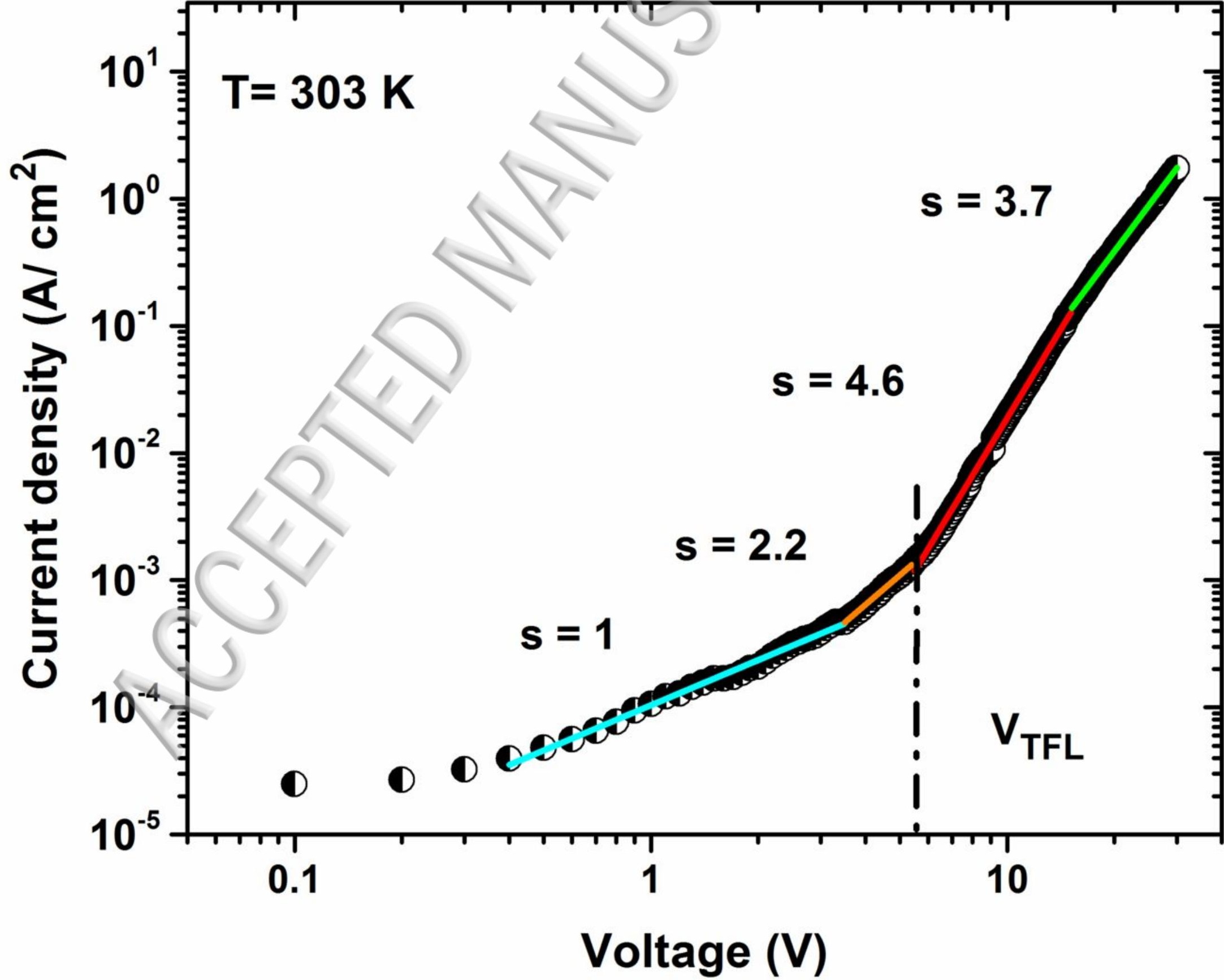




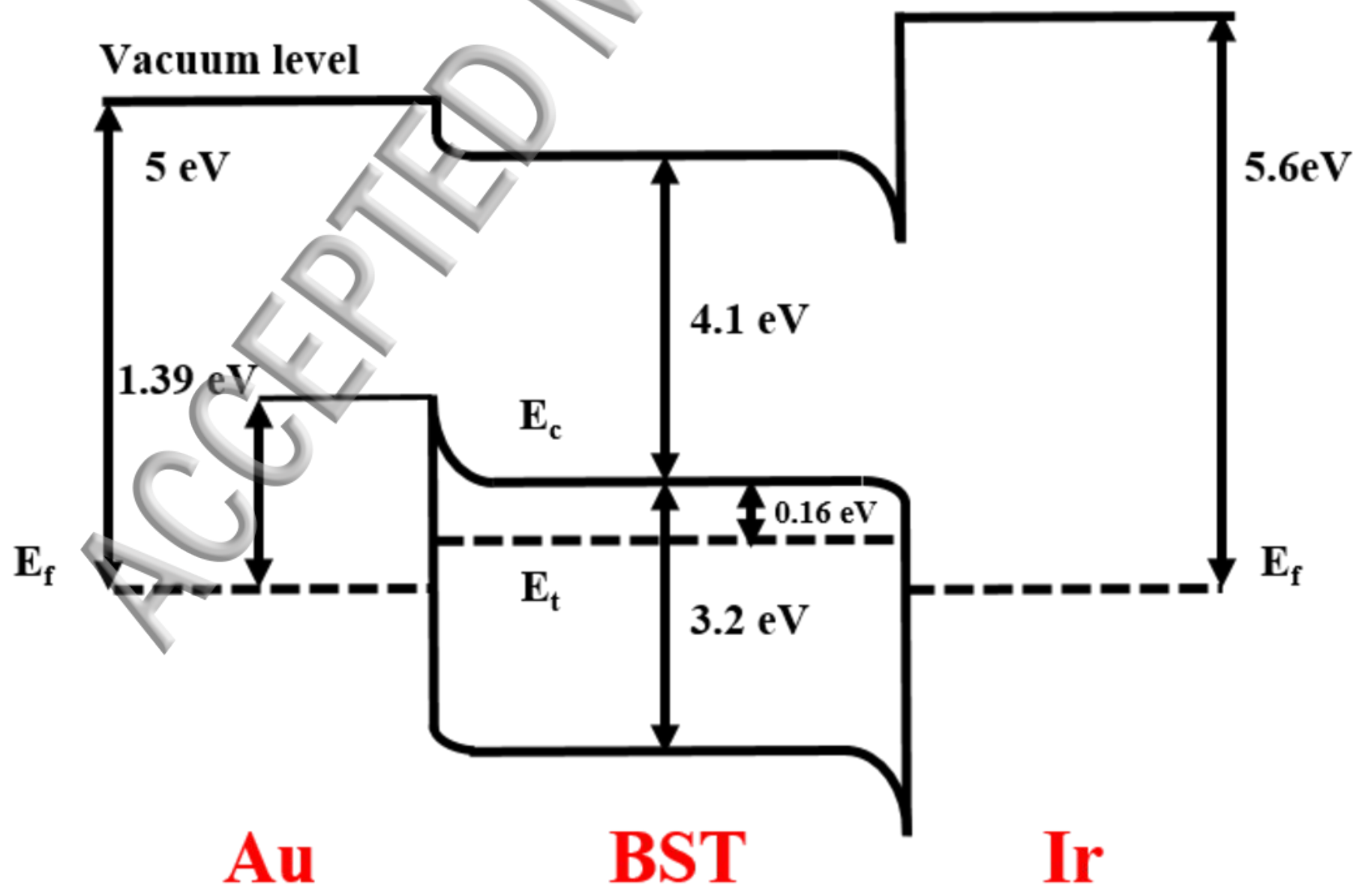




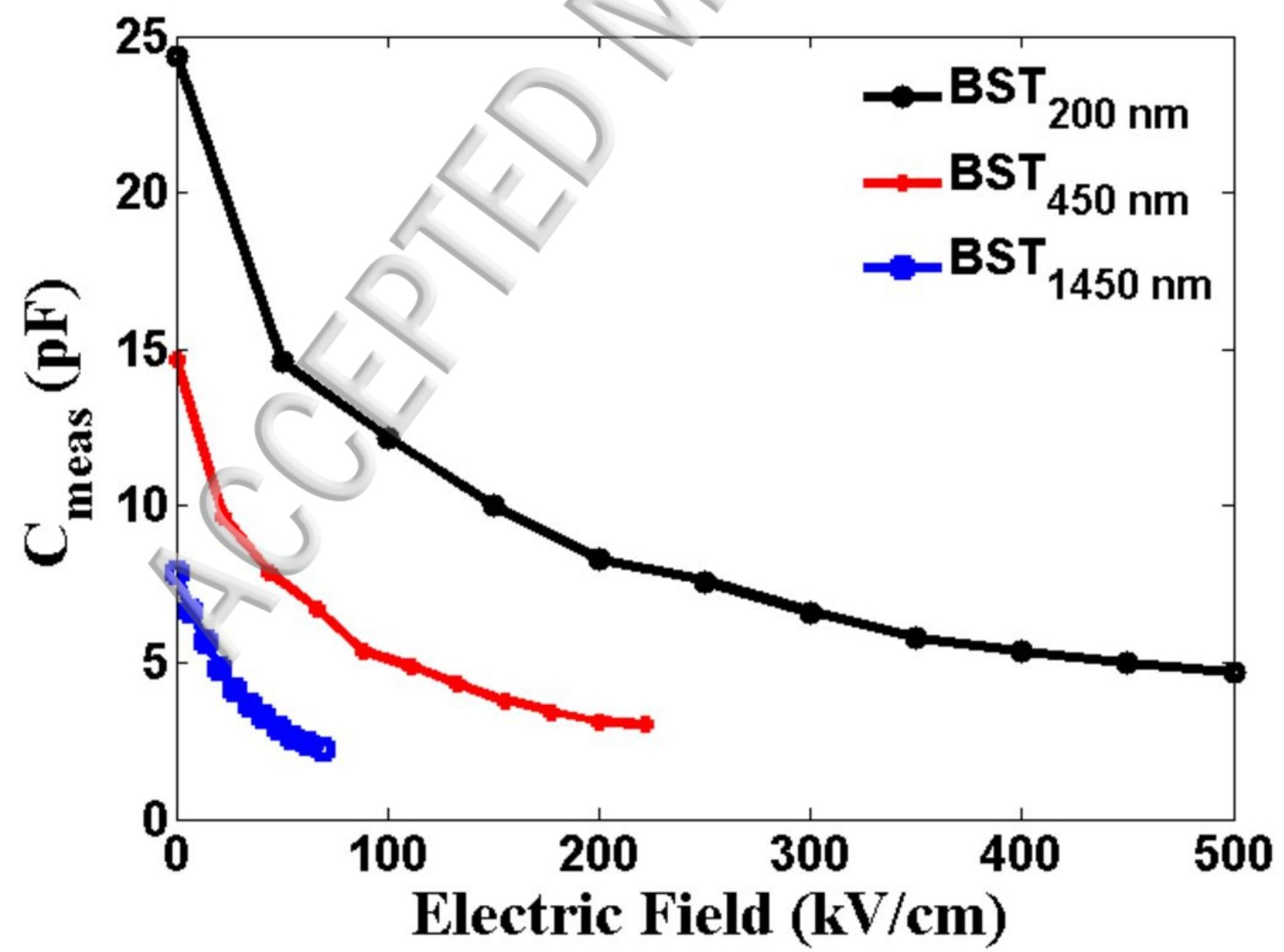




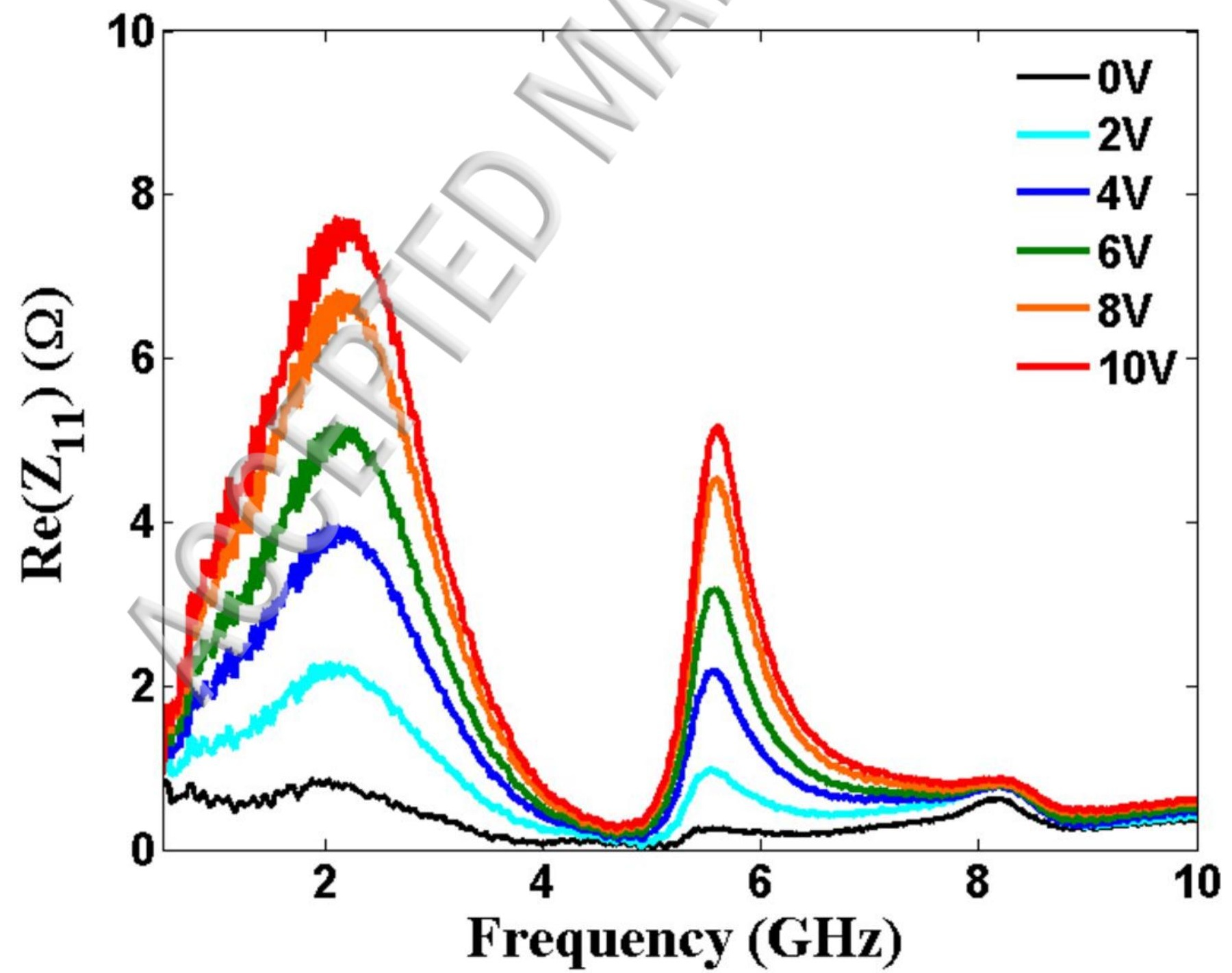




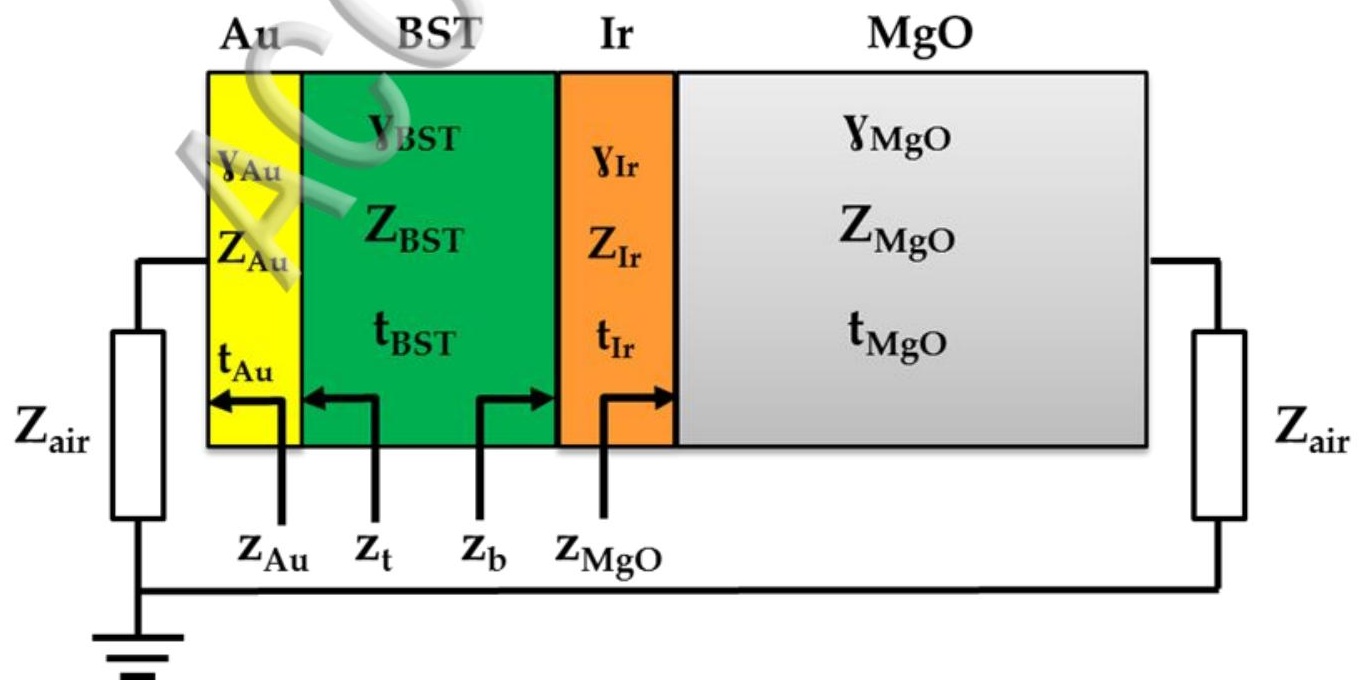




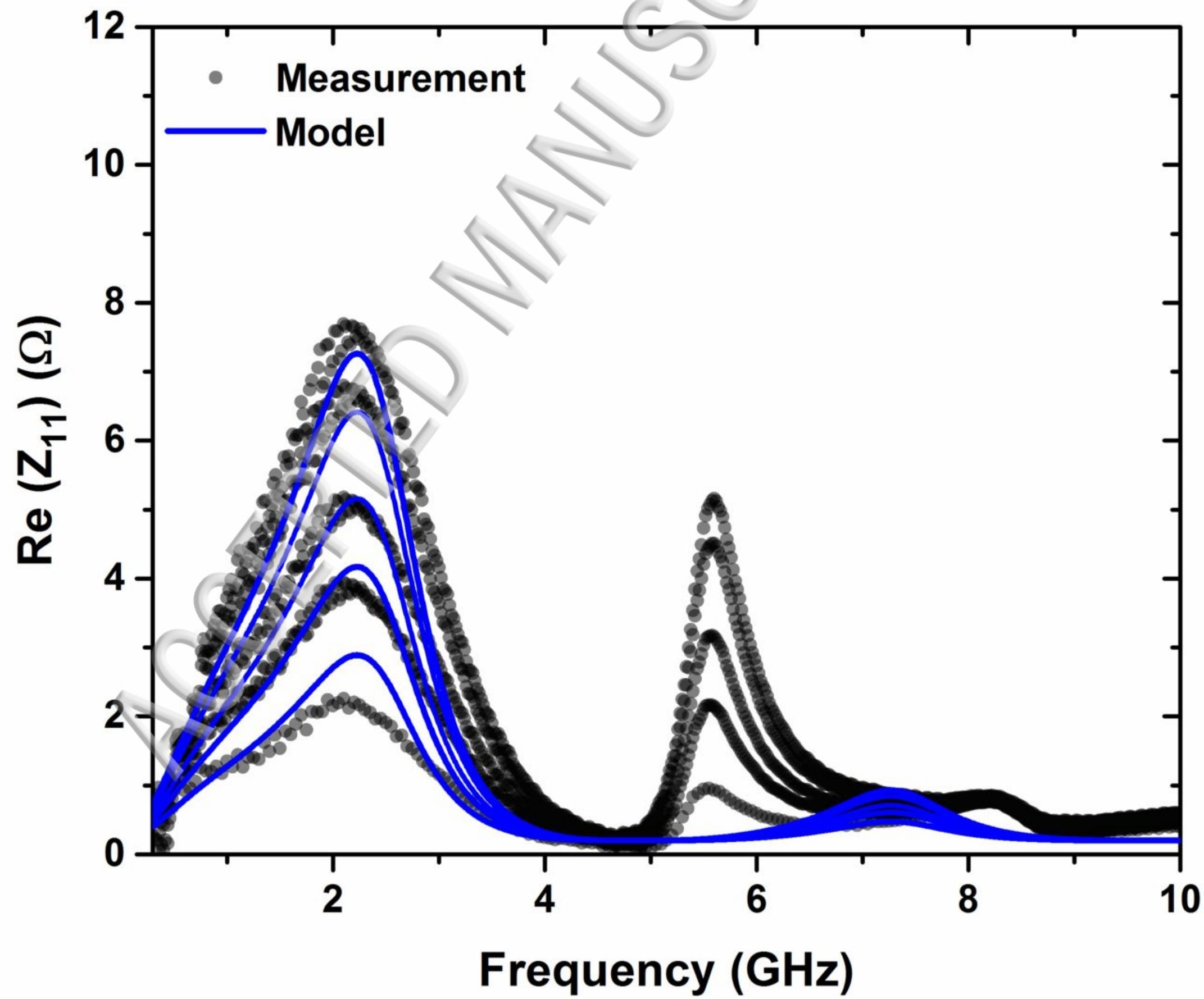




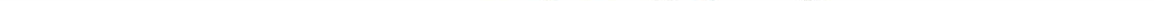

